\title{
THE PRACTICE LEVEL IN PARTICIPATORY DESIGN RATIONALE: STUDYING PRACTITIONER MOVES AND CHOICES
}

\author{
Albert M. Selvin \\ Verizon, USA, and \\ Knowledge Media Institute \\ The Open University \\ Milton Keynes, UK
}

\author{
Simon J. Buckingham Shum \\ Knowledge Media Institute \\ The Open University \\ Milton Keynes, UK
}

\author{
Mark Aakhus \\ School of Communication \& Information \\ Rutgers, The State University of New Jersey \\ New Brunswick, NJ, USA
}

\begin{abstract}
Most research in design rationale focuses on specific tools, methods, models, or artifacts. There has been relatively little attention to the practice level of design rationale work: the human experience of working with the tools and methods to create rationale artifacts. This paper explores a particular juncture of creativity and design rationale that is found in the special case of helping groups of people construct representations of rationale within live meetings. Such work poses challenges and requires skills different from those of individuals working alone. We describe the role of practitioners who perform caretaking and facilitative functions in collaborative or participatory design rationale sessions, and present a set of analytical tools aimed at making the practice level more visible. We locate the analysis in a theoretical framework aimed at understanding the experiential dimensions of such practice, including sensemaking, narrative, aesthetics, ethics, and improvisation.
\end{abstract}

Keywords: knowledge media, sensemaking, improvisation, reflective practice, aesthetics, ethics, narrative, grounded theory, facilitation, visualization.

\section{INTRODUCTION}

There are a variety of techniques used to foster creativity in design, such as brainstorming exercises and ideation workshops. Other articles in this special issue argue for or against the notion that design rationale techniques can spur creativity in the design process. In this paper we shift focus away from creativity as something that might be evoked through the collaborative creation of a design rationale artifact, and toward the ways in which creativity can

(C) 2010 Albert M. Selvin, Simon J. Buckingham Shum, and Mark Aakhus, and the Agora Center, University of Jyväskylä

URN:NBN:fi:jyu-20105241908 
manifest itself in the act of fostering creativity and engagement with such an artifact for others. These can be creative acts on the representation, creative ways of intervening in group process, or reframing participant utterances.

Creating representations of design rationale in collaborative groups requires a set of skills similar to other forms of participatory media practice. Understanding such practices calls for an empirical approach that can illuminate the sociotechnical, as well as aesthetic and ethical, considerations involved in evoking and representing information like design rationale, argumentation, and exploratory discussion within groups of people in live meetings. Our intent is to make this practice, with its particular conditions and challenges, visible and amenable to analysis.

While this approach can help with building better tools and methods for capturing design rationale, that is not our primary goal here. Rather, we aim to focus on the practice aspects of creating complex design rationale (DR) representations in groups. Our principal subject is not the participants in a collaborative DR session, although they are just as interesting in their own right. Rather, we are looking at the experience of people in the role of caretakers or facilitators of such events - those who have some responsibility for the functioning of the group and session as a whole. Collaborative DR practitioners craft expressive representations on the fly with groups of people. They invite participant engagement, employing techniques like analysis, modeling, dialogue mapping, creative exploration, and rationale capture as appropriate. Practitioners inhabit this role and respond to discontinuities with a wide variety of styles and modes of action. Surfacing and describing this variety are our interests here.

Good representations of design rationale do not come for free, and they often do not come easily. Proponents of DR tools and methods have long faced low adoption and even resistance to their approaches from many of their intended audiences (Buckingham Shum, 1996). Many researchers have explored this phenomenon, attributing it to factors such as the high cognitive overhead that the approaches seem to instill. For many would-be DR users, it requires considerable effort to move from customary forms of verbal and written argumentation, which seem to pour forth seamlessly, to the ostensibly more abstract forms of DR modeling, such as Rittel's Issue-Based Information System (IBIS; Kunz \& Rittel, 1970; see Figure 1). Even initially enthusiastic prospective adoptees often run into a variety of difficulties as they try to build their first DR representations, finding the rhetorical moves unwieldy or struggling with the software tools to express and manage things as they would like.

Compounding these challenges by attempting to construct such representations in groupswith the additional interpersonal issues, group dynamics, and usual issues of trying to get things done in meetings - would seem to be a recipe for failure. And yet, successful practitioners of collaborative and participatory DR, issue-based exploration, and argument or dialog mapping do exist. A small but growing community of such practitioners has moved well past the "Can it be done?" phase, and these practitioners have successfully applied their approaches in a wide variety of professional, organizational, and research settings. For such practitioners, further improving their practice involves understanding and deepening the skills required. However, little in the research literature addresses such skills and practices directly, let alone research advanced enough to use them as the basis for developing a body of principles and guidelines, as other professional practices rely on. This paper aims at supplying some foundational considerations for helping foster increased attention to, and development of, such practices. 


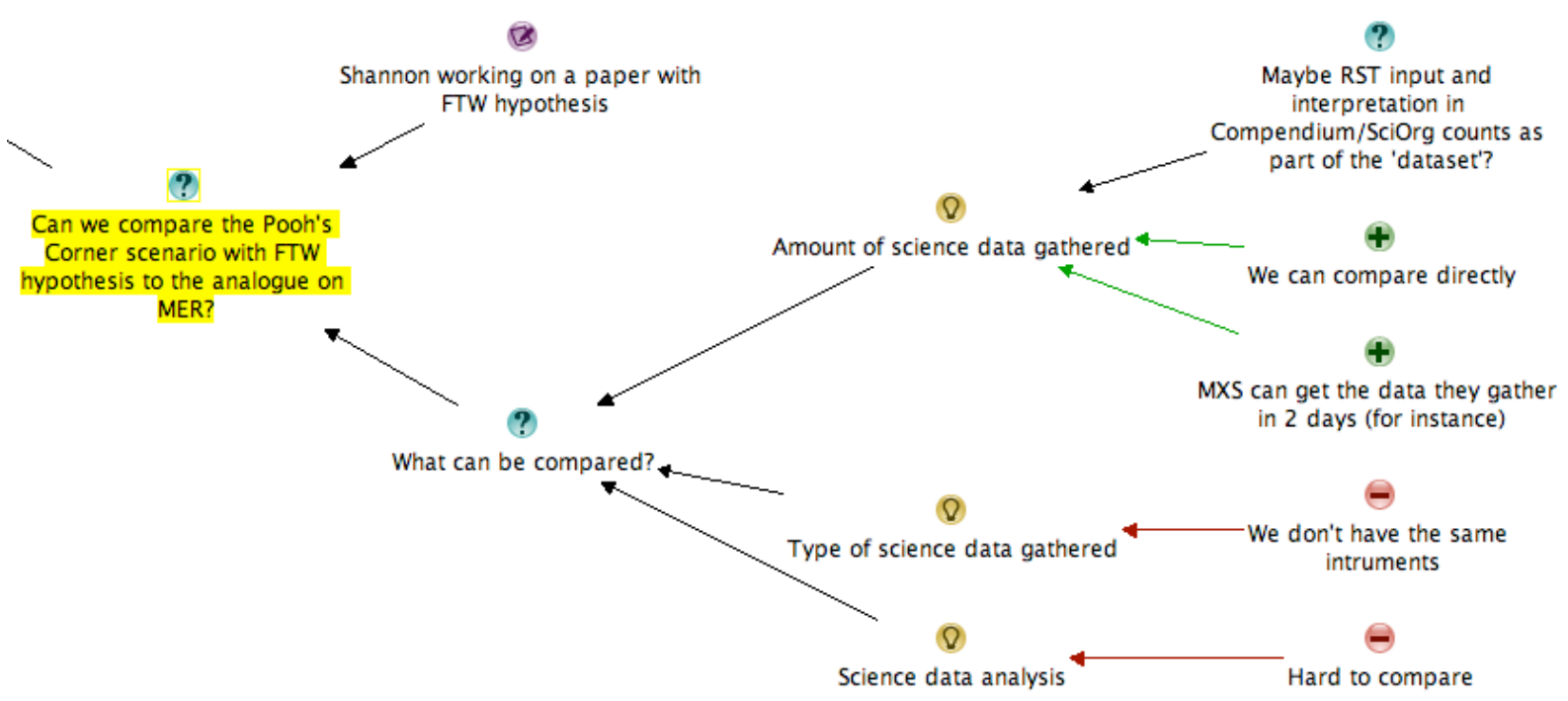

Figure 1. An example of an IBIS summary of a conversation, mapped during eScience field trials described in one of the case studies presented below. This can be contrasted with Figure 4, a much more constrained map largely generated by a software agent.

A note on terminology: There are many ways to refer to the practices we discuss in this paper, and the considerations described apply to other sorts of collaborative representations of knowledge besides design rationale. However for our purposes here we will use the abbreviation $P D R$ in the rest of the paper to stand for participatory design rationale.

We authors have spent more than 40 collective years studying, developing, and working with PDR and argumentation approaches, both in individual and group settings. We have trained others to work with such methods, including classes specifically for practitioners intending to facilitate collaborative and PDR modeling sessions. As members of international communities of similar researchers, practitioners, and tool developers, we share an interest (in varying ways) in the practice dimensions of the approaches. Through these experiences, we have identified a number of considerations that appear to characterize the practice level of PDR.

In the balance of this paper, we describe these practice studies, explain our methodology, and provide illustrative examples. We also describe the theoretical framework that is taking shape against the background of repeated rounds of investigation and reflection. Key research questions include:

- (RQ1) What is the nature of the skills required to construct graphical knowledge representations in real-time, participatory settings?

-(RQ2) What are the kinds of choices practitioners face, especially at sensemaking moments within the course of conducting sessions?

-(RQ3) How does the context of the service being provided affect the choices a practitioner makes? 


\section{AN EXAMPLE OF PDR PRACTICE}

What do we mean by the practice aspects of facilitating participatory design rationale? In this section we provide an illustrative example. ${ }^{1}$

A committee in a medium-sized public school district (approximately 20,000 students) in the Hudson River Valley region of New York State was tasked with analyzing the alternatives for school building capacity in the district, which has experienced declining enrollment. This highly contentious issue had come up many times before. The district's superintendent of schools was concerned that the discussion would be unproductive, due to tensions and unsurfaced assumptions between the various interest groups (school administrators, teachers, parents, taxpayers, etc.). Every school building has an active, vocal contingent of parents and teachers who have strong interests in keeping their own local school open. Equally strong and vocal are the many local taxpayers who feel that school taxes are already too high. To address this, the superintendent asked two outside practitioners with expertise in conducting PDR sessions to help run the meetings.

The practitioners convened a series of meetings in a library of one of the schools. A committee of twenty parents, teachers, community activists, and administrators met once a week to work through the alternatives. For each meeting, the practitioners prepared an agenda with a hypermedia issue mapping tool. ${ }^{2}$ The agenda focused on various alternatives, policy matters, process considerations, and other issues.

The practitioners employed a variety of approaches. First, they facilitated a general discussion of the issues involved, using a conventional IBIS approach (representing discourse as issues, positions, pros, and cons) to capture and display the discussion as it proceeded. This involved rapid synthesis of what the meeting attendees were saying, thus creating nodes and links in the hypermedia tool that showed the relationship of statements to each other. They also validated the way they captured the statements by frequently asking the participants to look at the maps, asking "Does this capture what you said accurately?" Sometimes participants looked closely and provided detailed feedback (e.g, "Well, not really. What I was really trying to say was this..."). At other times, the heat of the discussion was such that it was difficult for the practitioners to intervene without running the risk of derailing the meeting's momentum. The practitioners had to make moment-to-moment decisions on how much to intervene, and in what ways.

Between meetings, the practitioners analyzed the maps from the general discussion. They looked for recurring themes and questions and, from these, created a template covering the major considerations that would guide choices between the alternatives (see Figure 2). They then facilitated several sessions using the template to structure conversation about each of the alternatives in turn. By the fourth session, the facilitators were able to induce the participants to conduct an analysis according to the template, while still capturing as much of the side discussion and issues as possible. Also between sessions, the district office distributed via mail all of the map output in text form to all the participants.

At the end of the process, the practitioners held a plenary session for the broader community to understand the final decision. The maps of rationale and templated analysis made the pros and cons for each alternative, as well as many of the comments and points of view, clear and explicit. Even though there was little consensus that the chosen alternative was the best one, the community members completing a postpresentation questionnaire agreed that the 


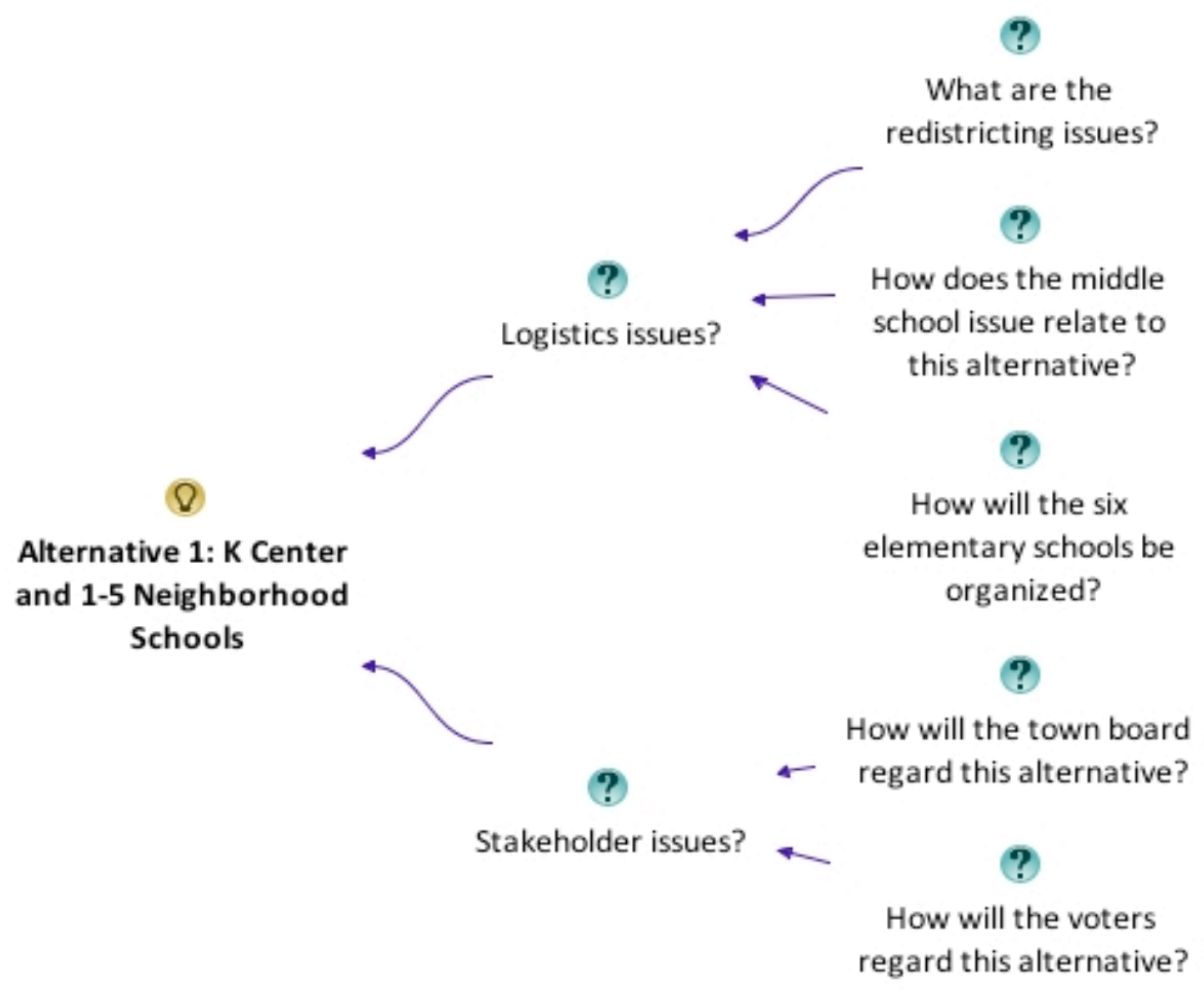

Figure 2. A portion of a meeting agenda, using a template to analyze alternatives.

process had been conducted in a fair manner, and that the discourse and competing points of view had been made more explicit and comprehensible than in previous years.

\section{A FRAMEWORK FOR UNDERSTANDING PDR PRACTICE}

Understanding practice like that described in the previous section requires taking into account a complex constellation of people, tools, representations, surroundings, and other factors. These have been summarized in the model shown in Figure 3.

The primary elements of the model are the people involved in creating the DR representation, and the representational artifact itself, as seen at the center of the diagram. The practitioner [a], which can be more than one person, orchestrates the participatory event and holds himself or herself responsible for its success. He/she is concerned with the quality and clarity of the representation and the participants' relationship to it. The practitioner takes primary responsibility for the form and content of the representation and the success of the session within its context [i]. As we saw in the example in the previous section, there can be 


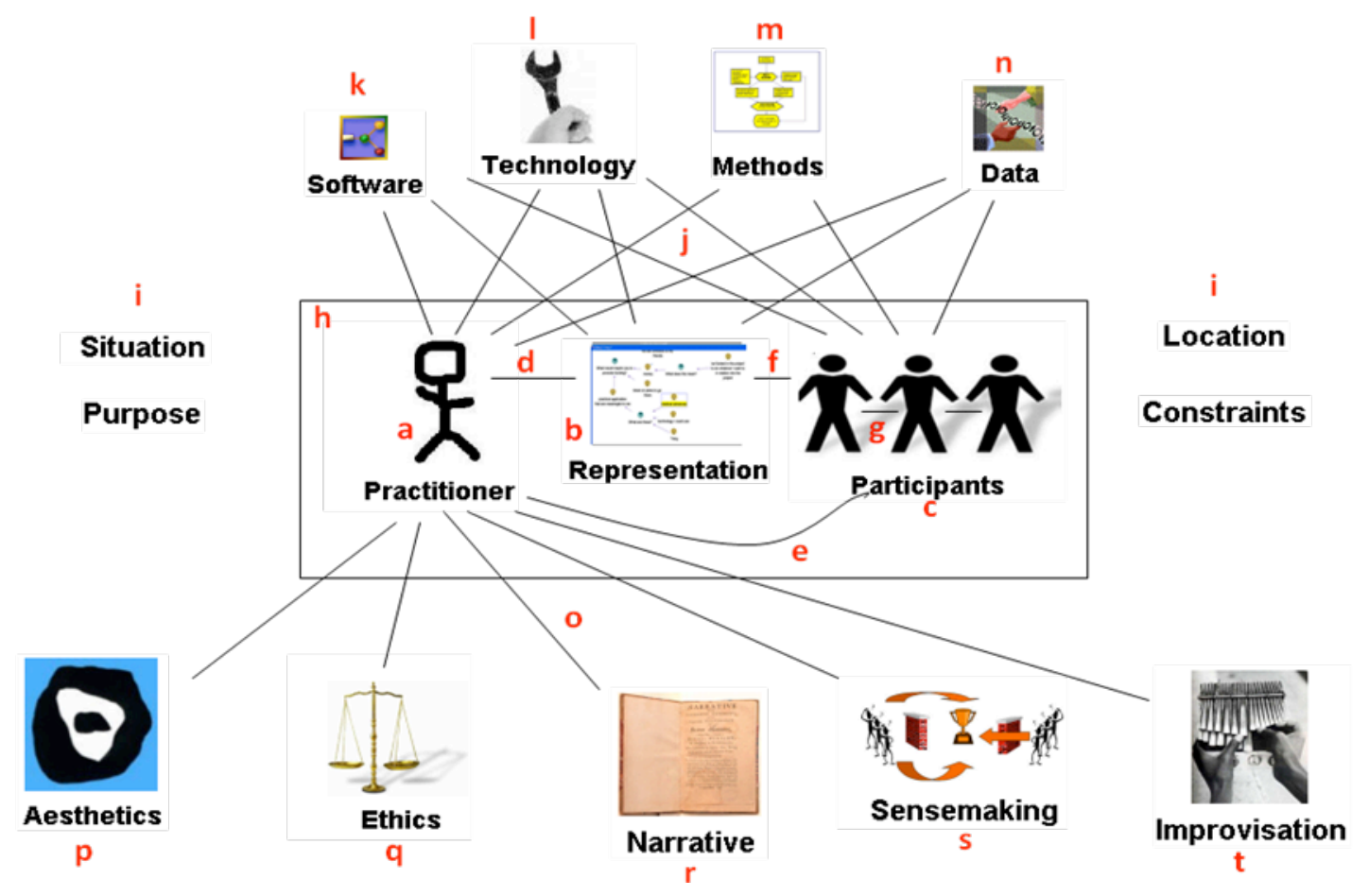

Figure 3. A framework for understanding participatory design rationale practice.

varying levels of intervention. The practitioners are not necessarily the ones with their hands on the equipment: Approaches where the participants themselves do the issue mapping directly are also possible (though often more difficult to carry out successfully). The practitioner interacts with the representation [b] as well as with the participants [c]. The nature of this interaction varies with the context and the specific role(s) that practitioners play in the activity system of the session. We follow McCarthy \& Wright (2004) in emphasizing the particularity and situatedness of individual, as distinct from collective experiences of and responses to the tools and methods used in PDR sessions. As such, we look for the unique and creative appropriations practitioners can make, especially in uncertain situations. These often shift in the course of a project, such as the varying ways that the practitioners in the previous section engaged the participants with the representation. Over time they grew to understand both the needs of the different parties involved (parents, teachers, administrators, community members) and the kinds of attention each group was likely to pay to them as outside consultants with a limited franchise to change the accustomed (and contentious) group process. Through extensive "backstage" discussion and work with the materials, they evolved the PDR templates and engaged participants in the representation.

The representation $[\mathrm{b}]$ can be any sort of DR or other type of representation, ranging from paper-based argument diagrams drawn on an easel sheet to software-based discourse models, such as the hypermedia representations used in the example above and that we will discuss in our case studies below. There can be multiple types of representation used in a session, including notes and action items. The participants [c] are the people in the room (whether a real or virtual space) taking part in the session. Although the diagram depicts the participants as identical figures, in fact they are quite unique. Being aware of and appropriately dealing with the diversity of participant personalities, relationships, and interests is a key practitioner skill, 
as well as an ethical imperative. Line [d] symbolizes the interaction of practitioners with the representation, which consists of actions on it (such as creating or modifying it), considering it, planning what to do with it, or even ignoring it. As with that of practitioners, participant interaction with the representation is best understood in a situated manner. Each party in the school capacity example had a unique perspective on the proceedings, the representation, and the other participants. For example, community members whose main purpose for attending was to speak out for lower taxes had to be convinced that a facilitated process would serve their needs, while the administrators who had arranged for the consultants to take part had to balance their anxiousness about both the outcome and the credibility of the process as it played out.

Line [e] shows the interaction of practitioner with participants. This can take many forms, even in a single session, such as facilitative interventions (keeping matters on track, making sure everyone is heard), questions and discussion, and process checks. It is a two-way stream, as participants also interact with the practitioners in various ways. Line [f] is the interaction of the participants with the representation, which ranges from passive to active, from directly engaged with considering it and making changes to it to ignoring it or giving it occasional once-overs. Line [g] shows the interactions of participants with each other, from collegial to disputatious to side conversations.

The three primary elements (practitioner, representation, participants) are contained within box [h], symbolizing the boundaries of the session itself, such as a specific meeting. Some efforts may consist of a single session, where some comprise many sessions (which may include individual DR mapping sessions as well as collaborative ones). The session is in turn located within its surrounding context [i]. The context includes the overall project in which the DR activity is taking place, the specific locations where sessions are held (including whether they are face-to-face, virtual, or a combination); the situation that contains the session, such as the project of which the session is a part, the organizations involved, and the problem domain; the purpose of the session, and the constraints operating in the situation, such as time, budget, attention, or other resource limitations. In the school capacity example, the sessions were the individual meetings held in the library, while the context included the immediate school capacity project, but also elements such as the history of previous attempts to resolve the issue, the relationships of the various participants, and the constraints of producing a report within a limited timeframe.

The lines [j] show the relations between the primary elements and what can be called the set of enablers: software [k], technology [1], methods [m], and data [n]. Each enabler is connected to each primary element, because all interact with each. (Note that methods are not connected directly with the representation; methods are always filtered through a person's actions.) Practitioners use the chosen software [k] to operate on the representation; there can be multiple software packages in use (or none). Participants may also use the software. The software in turn runs on whatever technology platform [1] is in use, such as laptop computers. Technology also includes whatever display tools are being used, such as LCD projectors, virtual meeting or telepresence rooms, and voting keypads (non-computer technology such as flip charts, markers, and whiteboards also count). During sessions, specific methods [m] will be employed, whether formal methods such as IBIS argument mapping or data flow diagrams, or informal methods like brainstorming or round-robin discussion. All of these operate on and draw from the data [n], which is the subject matter for the session, the 
conversations and ideas put forth and captured during the session, and any supporting material, such as reference information.

Finally, we turn to the dimensions that inform an understanding of practice and the practitioner experience itself. Lines [o] show the aesthetics [p], ethics [q], narrative [r], sensemaking [s], and improvisation [t] associated with the work of the practitioner. These dimensions by themselves do not constitute creativity in the aesthetic and/or improvisational sense, but they help us see how creativity emerges when practitioners respond to breakdowns and anomalies in the course of PDR sessions. In the need to intervene in a session to restore its forward movement, practitioner creativity can result in choice, action, and materials seamlessly coming together to resolve the breakdown. Practitioner creativity can be seen in the ways they draw from these dimensions in the moment of action. Since these dimensions form the basis for the analyses described later in this paper, we expand on them in the following section.

\section{DIMENSIONS OF PDR PRACTICE}

It can be tempting to treat the work of a PDR practitioner as simply one of following established protocols, or unnecessary where it is assumed that meetings and participants can take care of themselves. Yet even when there are no so-called facilitators in a meeting, usually someone, however informally, takes on aspects of the role of ensuring that the meeting reaches its goals. If a knowledge construction task is to be done (as opposed to simply listening to someone else give a presentation), someone will often jump up and take notes on a flipchart or draw a diagram on a whiteboard. This is just as much what we mean by practitioner as a paid professional who comes in to run the process and generate the products of a meeting.

In either case, when people act as PDR practitioners in our sense of the word, they inherently make choices about how to proceed [q], give form to the visual and other representational products [p], help establish meanings, motives, and causality $[\mathrm{r}]$ and respond when something breaks the expected flow of events [s], often having to invent fresh and creative responses on the spot [t]. These aspects of PDR practice are summarized in Table 1 and described in the following subsections. Although we present them as separate entities here for the purpose of description and analysis, in fact in they commingle in the experience of practice, as will be seen in the illustrative example at the conclusion of this section.

Table 1. Dimensions of Participatory Design Rationale Practice.

$\begin{array}{ll}\text { Practice } & \text { Definition } \\ \text { Dimension } & \end{array}$

$\begin{array}{ll}\text { Aesthetics [p] } & \text { How practitioners shape and craft the representation } \\ \text { Ethics [q] } & \text { How a practitioners' actions affect other people } \\ \text { Narrative [r] } & \text { Meaning and causality applied to the flow of events } \\ \text { Sensemaking [s] } & \text { The ways in which practitioners deal with situations of doubt or instability } \\ \text { Improvisation [t] } & \text { The spontaneous, creative moves that practitioners can make }\end{array}$




\section{Aesthetics [p]}

All diagrammatic DR approaches have explicit and implicit rules about what constitutes a clear and expressive representation. People conversant with the approaches can quickly tell whether a particular artifact is a "good" example. This is the province of aesthetics.

Aesthetics has to do with what human beings, in the moments when they are imparting expressive form via some medium (Arnheim, 1967), are actually doing: pulling together aspects of experience into a new whole that itself provides a shaped experience (Dewey, 1934/2005). The aesthetic dimension of PDR practice is concerned with the shaping and crafting of DR representations in response to both immediate and context-specific imperatives (things that must be done to help achieve participant and project goals), as well as to implicit and explicit concepts of right form. Using the lens of aesthetics offers a unique perspective on the relationship of a practitioner to the participants, emphasizing process, collective and participatory expressive forms, even ethical and political concerns (Cohen, 1997). Understanding the aesthetic dimension of a collaborative practitioner's work emphasizes how the encounter between participants, representations, and practitioner unfolds, the extent to which representation-building engages participants, and the ways in which participants are affected by the proceedings.

In explicitly incorporating the idea of aesthetics, we follow Dewey's (1934/2005) argument that aesthetics is not an elite, esoteric, or rarefied concept, even though it is treated that way in common usage. Rather, it is to be understood as the high end of a continuum from prosaic experience; it is a paradigm for "true," unalloyed experience. Aesthetics govern how we would experience any situation if the diluting, dulling, oppressive, or conflictual aspects were stripped away.

Our research investigates what distinguishes form-giving actions from other sorts, looking at the uniquely aesthetic characteristics of such actions in the work of a PDR practitioner. When working with groups, the boundaries of the world of experience are closely aligned with the situation in which they are operating - the people, goals, interests, and constraints of the project or team they are working with. Even within this bounded world, the dimensions and particulars of experience can be vast and diverse, so the problem - and hence the artfulness - of pulling them together into an "integrated structure of the whole" (Arnheim, 1967, p. 5).

For example, we look closely at how specific choices regarding form respond to the situation and express something of uniqueness (or fail to). Skilled practitioners can make choices in their actions on the representation that impart a complex of meanings and nuances.

\section{Ethics [q]}

The ethical dimension is concerned with the responsibilities of the practitioner to the other people involved, and to their various individual and collective needs, interests, goals, and sensibilities. In some situations, these responsibilities can be weighty in nature-for example, in situations of conflict or dispute, where every action and statement on the part of participants or practitioner holds the possibility of worsening the situation. In less fraught settings, consequences of action or inaction may be less severe, but can still have effects on the concerns of the participants or other stakeholders. Of particular concern are practitioner 
actions that affect the engagement of participants with each other, with the subject matter of their work, and with the nature and shaping of the representations. These often can take the form of questions: Should I do action $x$ or action $y$ ? What effect will it have on these participants if I do $x$ ? Should I intervene in their conversational flow? or Should I expend the effort to capture everything that person A is saying at this moment, or is the time better spent in cleaning up the map or preparing for the next activity?

Aakhus (2001, p. 362) advocates research into the communicative actions of facilitators, so as to "advance the normative level of communication practice." He stresses that facilitators' work is not just a neutral enabler of participants' decision-making, or a simple unfolding of a priori processes, but rather contains many instrumental aspects in which practitioner choices directly affect participants and the course of events during sessions of their work. He also examines the "transparency work" performed by communication practitioners in an ethical light (2002). This work, the result of active crafting on the part of the facilitator, is often invisible in accounts of practice. Aakhus (2003) further critiques frameworks that deemphasize the ethical responsibilities of particular mediation and group facilitation practices, arguing that "objectivity" is an inaccurate way to frame practitioner actions. Other researchers also examine choices and dilemmas faced by group support systems (GSS) facilitators (e.g., Yoong \& Gallupe, 2002). Facilitators do in fact intervene in their clients' situations. Schön (1983) argues for practitioners to take active and conscious ethical stances, recommending reflection-in-action as the means to achieve this. Our research identifies moments when practitioners make choices with such ethical implications. These often arise and pass quickly, such as the momentary shift in attention away from the participants that we see in the example presented below.

\section{Narrative [r]}

The narrative dimension concerns the connecting of diverse moments and statements over time, as well as the human experience of causality and consequences. Practitioner actions that have a narrative dimension - that serve to connect elements of the story being built in the DR representations for later telling and reading by others - contribute to the narrative shaping of both the effort itself and the representations that are the primary focus of their actions. Narrative is both a basic human developmental mechanism independent of any particular embodiment (Murray, n.d.) and an aesthetic form that can be represented in verbal, written, performed, or other forms. Narrative functions as a key human strategy for exploring and overcoming unexpected turns of events. Stories and story-making form a key psychological strategy for connecting disparate events. This is particularly so when there is a break or disruption from an expected course of events. "The function of the story is to find an intentional state that mitigates or at least makes comprehensible a deviation from a canonical cultural pattern" (Bruner, 1990, p. 49).

The skill of the storyteller lies in the artfulness and effectiveness with which he/she can craft an artifact that makes sense of the "breaches in the ordinariness of life" (Bruner, 1990, p. 95). Narrative is a central means by which we are able to glue together bits of experience to construct a new understanding. It is also a key part of human development, a way that we learn to construct and communicate understanding of events and environments. Further, narrative is an intentional form - things that are created, with varying degrees of skill, to serve various 
purposes. Approaches like scenario-based design employ narratives to capture both concrete detail and the inherent ambiguities in design situations, as well as to create communicative artifacts that can help bridge disciplinary differences (Rosson \& Carroll, 2009).

McCarthy and Wright (2004) point out that, as individuals, our interactions with technology can be understood through the prism of roles like author, character, protagonist, and coproducer. We are always actively engaging with technology as individuals with our own aims, history, emotions, and creativity, as much as we are also embedded in a sociohistorical context or attempting to perform some kind of task or composite activity.

In our approach, narrative analysis provides a frame for understanding practitioner efforts to maintain the coherence of representations even in the face of interruptions and potential derailments within sessions. Narrative provides a way to understand what coherence means in the context of a particular session (e.g., What is the intended arc of events? How is that arc meaningful to the participants? What roles do the various parties play and how are those important within the surrounding situation?). As well as looking at this encompassing framing of a session, we also look at the ways breaches of the expected occur, and how the practitioner as protagonist reacts to these. Finally, we look at the narrative aspects of the DR representation itself and how changes to the representation relate to the other narrative levels at play in and around a session.

For example, in one of our case studies that took place at a small workshop, the following narrative elements provided key context: There was a pre-existing set of conditions that framed the event, supplying expected causality, reasons for people to be at the event, expected roles, and assumed meanings. Some of the relevant narrative aspects included the ostensible purpose of the workshop, the personal reasons each participant had for attending (e.g., what they hoped to gain from it), the expected trajectory of the facilitated session itself, and the practitioner's own expectation that she would be able to capture and represent the discussion as it unfolded. When the session started to unravel due to a drift in focus on the part of participants (as well as the surfacing of some metadiscussion, like "Why are we talking about this?"), this constituted a breach for which the relatively novice practitioner had no ready-made, unproblematic response.

\section{Sensemaking [s]}

Creating DR representations is in itself often a way to help negotiate and construct a shared understanding (Weick \& Meader, 1993) of a situation or project as a whole. Within this larger frame, the act of representation itself engenders both negotiation as well as confusion, when the tools and discourse lose, if even momentarily, a clear sense of fit. In many design sessions, there are moments where forward progress is blocked because of unforeseen, uncontrolled, or otherwise problematic obstacles. Our research focuses on the sensemaking dimensions of the actions, and their consequences, that take place at such moments. They call for creative and skilled responses from whoever is playing a facilitative/representational role, since programmed or prescribed responses and rote actions are rarely sufficient in such situations.

Dervin's (1983) model of sensemaking posits that a person is always attempting to reach a goal, or set of goals. Goals themselves shift in priority and nature, in time and place. Some are explicit where others are tacit. The person moves toward these goals until an obstacle (a gap in Dervin's terminology) stops them. The obstacle impedes the person's progress and 
stymies efforts to continue. In order to resume progress, the person needs to design a movement (a bridge) around, through, over, or away from the obstacle. This can be as simple as asking someone for directions or help, or a complicated set of actions that may have a trialand-error character. "As an individual moves through an experience, each moment is potentially a sense-making moment. The essence of that sense-making moment is assumed to be addressed by focusing on how the actor defined and dealt with the situation, the gap, the bridge, and the continuation of the journey after crossing the bridge" (Dervin, 1992, p. 6970). These sensemaking actions can be understood as attempting to answer a set of tacit questions: What is stopping me? What can I do about it? Where can I look for assistance in choosing and taking an action? Weick and Meader (1993, p. 232) define sensemaking as the process of constructing "moderately consensual definitions that cohere long enough for people to be able to infer some idea of what they have, what they want, why they can't get it, and why it may not be worth getting in the first place."

Although in some ways sensemaking can be thought of as a perpetual, ongoing process (Weick, 1995), it is also something placed in sharp relief by encountering surprise, interruption, or "whenever an expectation is disconfirmed" (Weick, 1995, p. 14). Schön (1987, p. 19) characterizes such moments in professional practice as situations of "complexity, instability, and uncertainty," laden with "indeterminacies and value conflicts." Such moments are further defined by a "density of decision points" (Sawyer, 2003, p. 145). In professional practice, the moments where sensemaking comes to the fore can have the character of impasses (Aakhus, 2003) or dilemmatic situations (Tracy, 1989; see also Aakhus, 2001).

PDR practice can include many such moments. Our research looks at the particular character of practitioner sensemaking at those moments, especially as it is expressed through moves on the representations, explorations of and changes to them, and interactions with participants about them (Selvin \& Buckingham Shum, 2008, 2009). We consider in what ways DR representations, and the practitioners' interactions with them, contain both a source of obstacles and impasses, and a means of resolving or addressing them. In part, we focus on such moments because it is often where practitioner skill and creativity are most clearly manifested. In the example at the end of this section, we see a sensemaking trigger occur when participants discover that the geospatial data they had expected to see was missing from the artifact they were examining. We will see a further example described later in the paper.

\section{Improvisation [t]}

As discussed in the previous subsection, practitioners often encounter moments where they must deal with the unexpected events in the course of a PDR session. While some aspects of participatory DR practice follow predetermined patterns and draw on techniques and methods planned in advance, skilled practitioners often find themselves switching to alternative sensemaking strategies, or even improvising. It is the degree of creativity employed at this point that distinguishes the improvisational dimension of action from other sorts of sensemaking activities. Improvisation can be discerned in the freshness and innovativeness of the response to an event that triggers sensemaking.

Improvisation is difficult to control for, or measure in, laboratory or outcome-based studies of software tool use. Some research into meeting behavior, such as the use of GSS technologies, tends to regularize the practices surrounding the technology, analogous to 
similar moves to "script" teacher-student interactions (Sawyer, 2004) and otherwise de-skill or de-emphasize the creative aspects of many sorts of professional practices (Schön, 1983). Yet improvisation is central to understanding what truly occurs in real-world software use situations, especially where there are creative, unpredictable elements at play, such as constructing a representation of design rationale with a group of people in live conversation.

Sawyer (1999) discerns three levels at which to understand improvisation: individual (improvisation on the part of particular actors), group (improvised interactions within a bounded, particular situation), and cultural ("the pre-existing structures available to performers - these often emerge over historical time, from broader cultural processes"; p. 202). The cultural level supplies the elements of a practitioner's repertoire (Schön, 1983), the collection of pre-existing techniques and concepts (whether learned in school or from work or other experiences) that contain what the practitioner draws from, combines, and invokes in the heat of an encounter. Practitioners of exceptional skill often possess repertoires of great range and variety (Schön, 1983) that they are capable of combining in innovative, expressive, and subtle ways. This kind of characterization is particularly apt when a practitioner is confronted with a situation of confusion or uncertainty, where he/she can no longer continue on with a single preexisting method or technique (though a return to it later is possible) and must make rapid decisions about what actions to take and ways to inflect those actions, or risk losing the coherence of the session, thus jeopardizing its goals.

Maintaining an awareness of the emergent aspects of a situation, however, does not mean that all is left to chance. Sawyer (2004, p. 12) emphasizes the concept of "disciplined improvisation," which juxtaposes improvisational aspects of practice (dialogue, sensemaking responses, spontaneous and creative acts) with "overall task and participation structures," such as "scripts, scaffolds, and activity formats." Skilled practitioners are able to navigate judiciously between moments when they can rely on pre-existing structure and scripted actions, and moments calling for fresh responses and combinations. In a PDR session, improvisation can take many forms, such as sudden shifts in stance or tool strategy. Often these are miniimprovisations that occur and conclude rapidly, unplanned and not referred to verbally in the course of other sorts of actions. This is seen in the example below, which discusses a sensemaking trigger, an improvised response, and the aesthetic dimensions of the response.

\section{An Example}

By way of illustrating some of the phenomena discussed above, here we present a highly abbreviated portion of an analysis of one of the episodes from a case study.

Figure 4 shows the result of an episode of improvisation on the part of an expert practitioner that took place between $61 \mathrm{~m} 27 \mathrm{~s}$ and $63 \mathrm{~m} 12 \mathrm{~s}$ of a $2 \mathrm{~h} 15 \mathrm{~m}$ session. In the context of NASA field trials (Clancey et al., 2005; Sierhuis \& Buckingham Shum, 2008), a distributed team was working through auto-generated maps of science data associated with a robotic rover trial. The team suddenly realized that some of the expected data (geographic waypoints) were missing from the map.

As soon as he heard the participants commenting in surprise about this ("What waypoint is this?"), which constituted the sensemaking trigger, the practitioner spontaneously launched a search for potential sources of the missing information, opening and inspecting the contents of several other maps. 


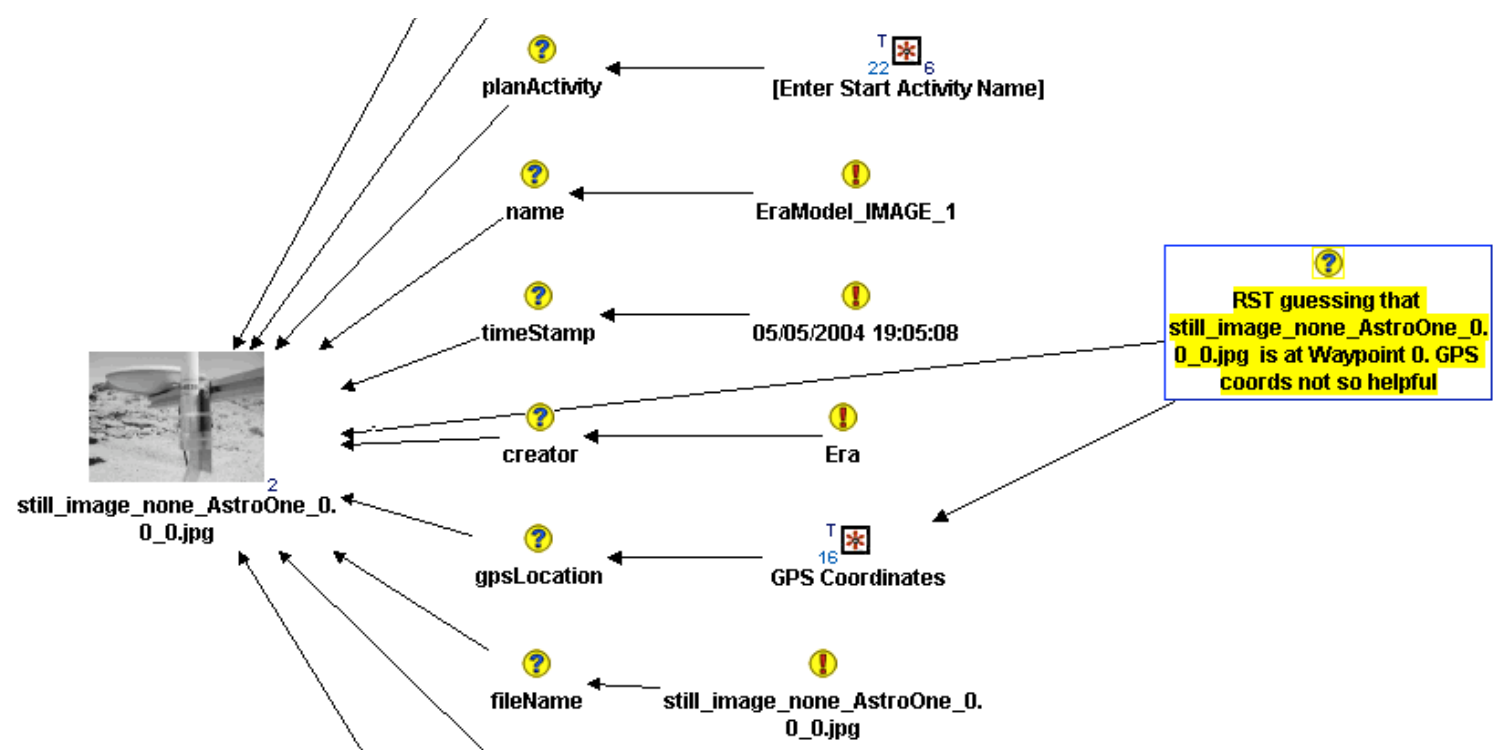

Figure 4. Portion of a screenshot from Mobile Agents project, showing an improvised response to a sensemaking trigger.

After determining that he could not find the waypoint information either, and while listening to the participants discuss their own attempts to locate the data in other records, the practitioner returned to the initial map and created a question node (highlighted in yellow in Figure 4) capturing the preceding deliberation from the participants. This was impromptu, not directed by the participants and not in response to any particular coda in the conversation. The practitioner determined that the group would not be able to get any more information to inform the waypoint determination than what they had just said.

The practitioner made several aesthetic choices during this event. He chose an area in the white space to the right of the imported science data nodes, implying or emphasizing by this choice that the new node is a comment on the science data rather than an addition to it: It is outside of the pre-existing imported science data. He also chose to link the node to the main image node, drawing the link across all the other nodes in the view, which serves to make it more dramatic, and possibly effective, emphasizing the disruptive quality of the missing information and the effect it had on the session. He makes a textual aesthetic choice in his use of the gerund guessing to imply the unfolding, transitive nature of the comment in the node. If he had used the past tense ("RST guessed"), it would not have conveyed the same process sense of the moment. He also chose to link it to the GPS Coordinates map node, indicating that the node is also commenting on the data contained in that map.

\section{Summary}

In our approach, we see the concepts of narrative, sensemaking, and improvisation as providing complementary frames for interpreting instances of practice. Narrative theory provides ways of looking at the container, purpose, intention, and gives the context for the breaches that occur. Sensemaking looks particularly at the breaches and the ways in which actions and representations respond. Improvisation within the context of sensemaking is 
where we can often most clearly see practitioners demonstrate relative levels of skill and artistry. All of these have both aesthetic and ethical dimensions.

These dimensions are not usually explicit in our source data. Caught up in the proceedings as they are, it is not often that a practitioner or participant in a PDR sessions will directly comment on the narrative framing or aesthetic shaping at work. We have had to develop a number of tools to help us discern and analyze how the dimensions of our framework are manifested in instance of actual practice. These are described in the following section.

\section{STUDYING THE PRACTICE LEVEL}

In this section we describe how we analyzed the ways in which the above dimensions play out in situations of actual PDR practice. As befitting exploratory work in an underresearched domain, we have employed qualitative research techniques to identify themes and hypotheses through close analysis of video and screen recordings of PDR sessions. Qualitative approaches, such as grounded theory (Strauss \& Corbin, 1990), are generally regarded as appropriate when a field or phenomenon is in its early stages, and when research problems and theoretical issues are not yet well defined. In addition, many of the considerations that the practitioners we are studying must deal with are emergent in character, responding to the unexpected events and anomalies that intrude on even the most carefully planned sessions. Indeed, sensemaking considerations form the core of our analysis here, since being able to resolve the anomalies they encounter is a key success factor for the practitioners we study. The ability to diagnose and repair breakdowns by drawing on a pre-existing "repertoire of expectations, images, and techniques" (Schön, 1983, p. 60), as well as fresh creative responses in a near instantaneous fashion, is the hallmark of successful professionals of many kinds, and is no less the case for the practitioners we study.

\section{Source Data and General Approach}

We have studied both experienced and relatively inexperienced practitioners. These include several in-depth microanalyses of long PDR sessions, looking at how highly skilled practitioners encounter and solve sensemaking challenges in the course of working with their participants (Selvin, 2008). The settings were in situ sessions, often several hours long, held as part of larger projects, where the tasks carried out emerged from the highly contextual needs of those projects (such as a NASA remote science team looking at geological data during virtual meetings over a week-long field trial). We also conducted experiments where teams of mostly novice practitioners planned and carried out a facilitated session for their peers on the theme of space travel. In both types of studies, our primary data are video and screen recordings of the sessions. We analyzed these recordings using a grounded theory approach (Strauss \& Corbin, 1990), paying special attention to participant and practitioner verbal statements, practitioner actions, and "moves" on the DR representation itself (changes done to the representation, such as adding a node or editing label text).

The analysis focused on characterizing the choices made by the informants in their preparation period (what they were trying to achieve, how they organized the base materials using the software, their intended flow of events, the roles they assigned, the software aspects they intended to leverage) and in their enacting these during group sessions. Using critical 
incident analysis (Tripp, 1993), we then selected moments where practitioners were faced with some kind of anomaly in the course of a session. We looked at the specific practitioner moves and choices that determined the outcome of the sensemaking moment, focusing on the aesthetic, ethical, improvisational, and narrative aspects of those moves and how these contributed to the ways in which participants engaged with the representation, with special emphasis on the character of the real-time shaping of the representation. Through repeated viewings and application of a number of analytical instruments (described below), we built up explanatory concepts, categories, and properties, focusing on the engagement of both practitioner and participants with the hypermedia representation.

\section{Iterative Development of Analytical Tools}

The five tools described below emerged from repeated rounds of analysis and reflection. In each, we started from the data (the recordings of PDR practice) and identified patterns and concepts that appeared to recur in the moves and statements contained in the video recordings. Early on, we concentrated on the move-by-move level and developed a finegrained instrument with a number of categories derived from open and axial coding on the contextual meaning of each move and statement in a session. We identified sensemaking triggers in those sessions, moments where something disturbed the expected flow of events and forced the practitioner to do something different, often requiring creative improvisation to resolve the episode and return the session to its intended track. We then wrote narrative descriptions of these episodes, starting with the sensemaking trigger, describing the actions within the episode, and explaining how the episode was brought to closure.

While this approach produced a large amount of richly described data, several limitations became apparent. First, it was extremely time-consuming to apply the 18 analytical categories to each move and statement of a 2-hour session, which might contain over 1,300 moves and statements. A grid analysis of a single $2 \mathrm{~h} 15 \mathrm{~m}$ session required almost 24,000 cells in a spreadsheet. Second, important aspects of the context itself seemed to recede as we concentrated on the individual moves. Without losing our focus on the meaning of individual moves, we needed a way to frame those moves that could more clearly connect them to their context, especially in ways that allowed us to identify the aesthetic and ethical dimensions informing the moves. This led us to develop two further instruments. The first provided a way to characterize the aesthetic "shaping" that both was intended (planned) and actually occurred during a session. The second was a distillation of the more finely-grained concepts and categories from the grid analysis that allowed us to characterize broader timeslots in a session with a more manageable set of three criteria derived from our open and axial coding. Both of these processes gave us the means to frame the episodes covered in the other analyses in the context of the session as a whole, in such a way as to highlight our dimensions of interest at all three levels of granularity (session, timeslot, and move).

Finally, we wanted a way to connect the results of these analyses more explicitly to the dimensions of our theoretical framework. This led us to create the "framing" tool. Its categories and questions are derived from the framework, conceived as an ideal, normative model for how a practitioner should act in a PDR situation. This allowed us to compare what actually happened in a session to an ideal model, so as to highlight how practitioner choices moved either 
Table 2. Summary of Tools for Analyzing Participatory Design Rationale Practice.

\begin{tabular}{ll}
\hline Analytical Tool & Description \\
\hline Shaping form & $\begin{array}{l}\text { Characterizing the representational character of the whole session to } \\
\text { delineate the intended and actual shaping that took place }\end{array}$ \\
CEU analysis & $\begin{array}{l}\text { Mapping the coherence, engagement, and usefulness (CEU) } \\
\text { dimensions of timeslots within the session. Aids in identifying } \\
\text { sensemaking episodes }\end{array}$ \\
Narrative description & $\begin{array}{l}\text { Rich description of a sensemaking episode, including dialogue and } \\
\text { descriptions of events } \\
\text { Grid analysis }\end{array}$ \\
Framing analysis & $\begin{array}{l}\text { Micro-moment moves and choices during the episode } \\
\text { Characterizing the practitioner actions during the episode in aesthetic, } \\
\text { ethical, and experiential terms }\end{array}$ \\
\hline
\end{tabular}

closer or farther away from ideal behavior. The full set of analysis tools is summarized in Table 2 and described further in the following sections. ${ }^{3}$

\section{Analytical Process}

For each of the PDR sessions we analyzed, we employed the analytical instruments described above in the sequence represented in Figure 5. By applying this set of tools, we aimed at achieving both qualitative triangulation (Fortner \& Christians, 1981) and increasing theoretical sensitivity (Strauss \& Corbin, 1990) by looking at the data through multiple lenses.

We started by viewing the video recordings several times and creating a transcript of the entire session. Then, for each of the tools, we viewed the recordings again with the specific lens provided by that tool, which are described below.

\section{Shaping Form}

The shaping form comprises a set of questions asked about the session as a whole. It aimed at characterizing the representational character of the session. We described what kinds of roles participants and practitioners played in the shaping of the representation, both as a result of planning and intention, and in response to whatever exigencies actually occurred during the session.

The questions included a characterization of the overall ecosystem of the session (the surrounding context, purpose of the session, types of participants), as well as a number of questions designed to put focus on the interaction of people with the representation. Table 3 relates the questions to the dimensions of the framework.

\begin{tabular}{|c|c|c|c|c|}
\hline Transcript & Shaping form & $\begin{array}{c}\text { CEU } \\
\text { analysis }\end{array}$ & $\begin{array}{c}\text { Narrative } \\
\text { description }\end{array}$ & Grid analysis \\
\hline
\end{tabular}

Figure 5. Analysis sequence. 
Table 3. Relation of Shaping Form Questions to Dimensions of Participatory Design Rationale Practice.

\section{Shaping Form Question}

What shaping was intended (how the session was planned to work, what shaping the planners intended to occur, and how it would be accomplished)?

What was the level and quality of participant and practitioner engagement (with maps, subject matter, process, environment)?

What types of shaping actually occurred during the session?

If the intended shaping went awry, why did that occur? What blocks an intended shaping? How are the blocks resolved or avoided?

Who did the shaping, for what reasons? What contributions to the shaping occurred?

How were decisions about shaping made? What kinds of decisions were they? Who made them, on what basis?

How were these decisions taken up into the representation itself (if they are)? Which are ignored or dropped? Why?

\section{Relation to Framework}

Shaping itself is largely the province of aesthetics $[p]$, the construction of meaningful form. This question refers to the planned or intended sorts of shaping (which may or may not have occurred in the actual session).

This question concerns the relationships of participants, practitioners, and representation to each other [framework elements $d, e, f, g$ ], as well as to the surrounding context and resources [i, j].

Means to report what sorts of aesthetic shaping [p] took place in the actual session.

Identifies what sensemaking [s] triggers may have occurred, placing them in the context of the overall narrative trajectory of the session [r]. Explores the degree of improvisation [t] in resolving or avoiding obstacles to progress.

Maps the shaping actions [p] onto the way their performers related to the representation $[d, f]$.

Looks at the choice making involved in both shaping actions and participant inclusion or exclusion in those actions. Often the clearest way to discern the situational ethics [q] of the practitioners.

The result takes the form of a narrative document, (e.g. Figure 6).
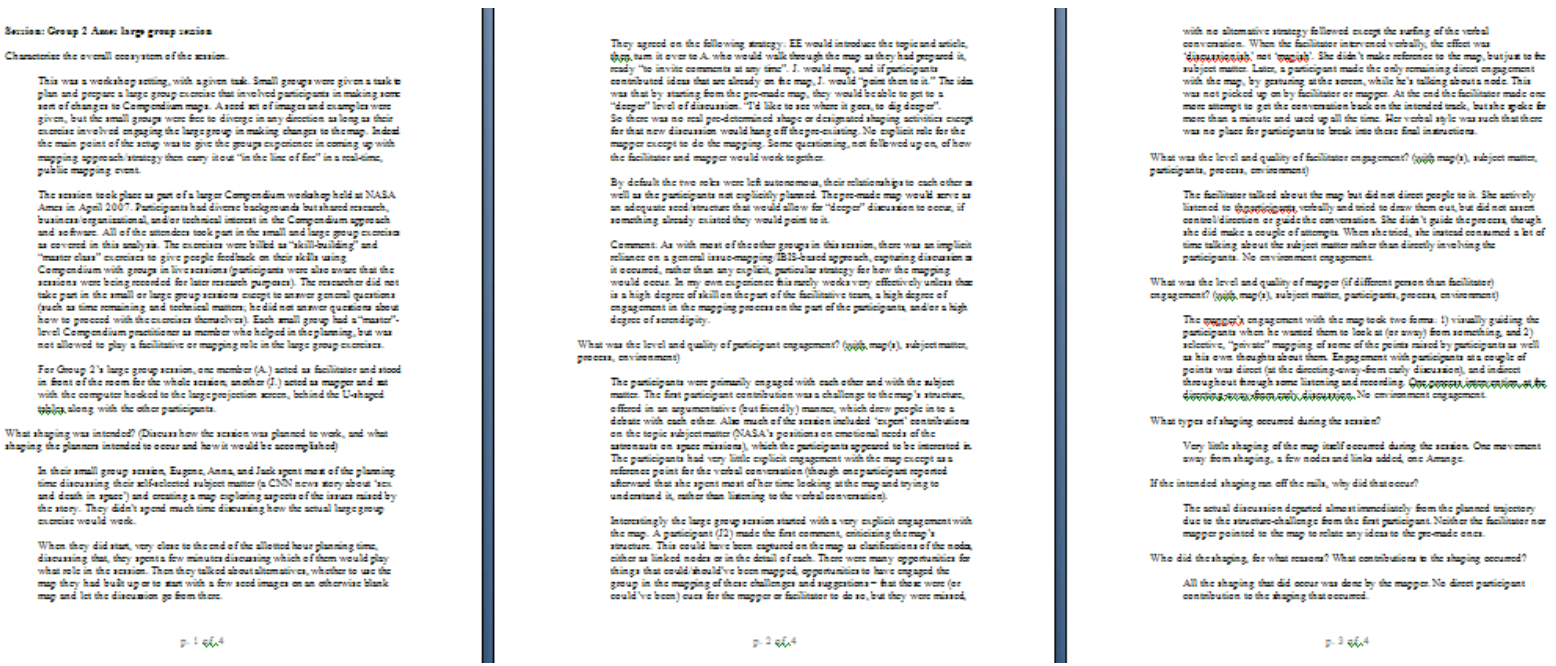

Figure 6. Example of a completed shaping form. 
With the overall character of the representational role described, we now use the CEU tool to zoom into a lower level of detail to characterize the session as it unfolds over time.

\section{Coherence, Engagement, and Usefulness (CEU) Analysis}

In this analysis, we coded the CEU dimensions of each timeslot to build up a signature (in the sense of a distinctive pattern that indicates the character) for the session. When visualized as a grid, this provides a gestalt view, showing the extent to which the representational artifact being maintained by the practitioner was co-constructed by participants, in a way that seemed to add value.

Coherence involves keeping the information display, and the interaction of participants with it as well as with each other, understandable, clear, evocative, and organized. At any moment, the meaning and organization of the visual and textual elements of the display should be clear to participants (as well as practitioners). Engagement refers to the relationship of participants to artifacts in sessions involving any sort of representation, whether a whiteboard, easel sheet, or software projected in front of the real or virtual room. The value of the representation is directly related to the degree that the participants are engaged with it whether they are looking at it, talking about it, referring to it, and involved in its construction or reshaping. Usefulness refers to the extent to which the representation appears to be adding value for the participants and helping to fulfill the predetermined or emergent goals of the session. It is the responsibility of the practitioners to make sure that the representation is a useful part of the proceedings.

We divided the video and screen recordings into 30-second timeslots. For each timeslot, we rated how the session had fared in that timeslot in terms of the CEU of the relationship of the participants to the hypermedia display. There are three ratings: High (three points), indicating a high or strong degree of engagement, coherence, and usefulness; Medium (two points), indicating a medium or average degree of the three criteria; and Low (one point), indicating that there was a low degree during that timeslot. Table 4 provides a set of examples illustrating how each rating is derived from the video data. The way we arrived at each rating was derived from the specifics of the session and timeslot itself, and thus vary in what we looked for and were able to discern in the data. Some ratings were assigned based on participant comments or observations of practitioner actions, while others by examining the representational artifact itself at that moment in time in the context of the current participant statements or actions.

For example, the DR representation in a specific timeslot might display a high degree of clarity and "readability"; all the content is legibly presented and laid out, and is faithful to the statements, tone, and purpose of the meeting (at least of its current activity). Thus we would rate both Coherence and Usefulness as High (3 points each). However, at that moment the participants are caught up in a side topic and are not paying attention to the representation, therefore we would rate Engagement as Low (1 point).

By assigning a color to each rating in the spreadsheet, we generate heat maps that provide a gestalt visualization of the whole session in terms of the three criteria. Figure 7 shows a comparison of CEU heat maps from six different sessions. Such heat maps make it possible to identify the overall tenor of the session, and to point out where sensemaking moments, or breakdowns, may have occurred-typically when the $3 \mathrm{~s}$ (High ratings, green shading) drop to 
Table 4. CEU Ratings and Exemplars.

\begin{tabular}{|c|c|c|c|}
\hline Criteria & Low & Medium & High \\
\hline Coherence & $\begin{array}{l}\text { The representation is } \\
\text { unclear or bears little } \\
\text { fidelity to the current } \\
\text { focus of interest; e.g., a } \\
\text { participant remarks that } \\
\text { "I don't see what we're } \\
\text { talking about" on the } \\
\text { map. }\end{array}$ & $\begin{array}{l}\text { Moderate level of } \\
\text { coherence, e.g., some } \\
\text { confusion about the } \\
\text { meaning of the way } \\
\text { various nodes on the map } \\
\text { are tagged, but generally } \\
\text { the representation is clear } \\
\text { enough to follow. }\end{array}$ & $\begin{array}{l}\text { The representation is a } \\
\text { clear reflection of the } \\
\text { discussion or exercise, in } \\
\text { form, content and } \\
\text { organization. All } \\
\text { participant contributions } \\
\text { have clear places to be } \\
\text { entered and linked on the } \\
\text { map. }\end{array}$ \\
\hline Engagement & $\begin{array}{l}\text { The participants are } \\
\text { paying little or no } \\
\text { attention to the map; } \\
\text { e.g., some participants } \\
\text { are having a side } \\
\text { conversation with no } \\
\text { reference to the map. }\end{array}$ & $\begin{array}{l}\text { An example is when } \\
\text { participants start to make } \\
\text { side conversation while } \\
\text { practitioners are in the } \\
\text { midst of making a } \\
\text { complicated change to the } \\
\text { map, rendering it } \\
\text { temporarily less than } \\
\text { clear. }\end{array}$ & $\begin{array}{l}\text { Participants are looking } \\
\text { at, talking about, and } \\
\text { appearing to care about } \\
\text { what is on a map; e.g., a } \\
\text { participant validates that } \\
\text { the way the practitioner } \\
\text { has captured his/her input } \\
\text { on the map is accurate. }\end{array}$ \\
\hline Usefulness & $\begin{array}{l}\text { The representation is } \\
\text { not acting as a tool } \\
\text { toward the realization } \\
\text { of the session's } \\
\text { purpose; e.g., the map } \\
\text { is no longer keeping up } \\
\text { with either the intended } \\
\text { exercise or the } \\
\text { emergent conversation. }\end{array}$ & $\begin{array}{l}\text { This is evident when it is } \\
\text { partially, but not } \\
\text { completely, clear to the } \\
\text { participants how the map } \\
\text { will help them complete } \\
\text { the exercise. }\end{array}$ & $\begin{array}{l}\text { Indicates that the } \\
\text { representation is integral } \\
\text { to the achievement of the } \\
\text { session's purpose; e.g., } \\
\text { the structure put in place } \\
\text { for the exercise is working } \\
\text { efficiently; participants } \\
\text { understand the sequence } \\
\text { of events and actions. }\end{array}$ \\
\hline
\end{tabular}

$2 \mathrm{~s}$ (yellow) or 1s (red), indicating that the representational artifact seemed to add little or no value at that moment. When a session has High ratings throughout, it can indicate that the preparation and execution of the session (design and realization) were both well thought out in advance and handled in practice. In such sessions, possible breakdowns are avoided, often through the expertise of a practitioner.

Figure 7 also shows an overview of the sensemaking character of six of the sessions studied. This visualization shows that three of the Ames sessions contain a fair amount of red cells, indicating Low ratings for one or more of the CEU elements (possibly reflecting the relatively novice level of most of these sessions' practitioners). These are moments in the session when the session went somewhat awry in terms of the practitioners' intentions for having the group co-construct the representation. These would be prime locations to look for the sensemaking triggers (what set off the drop in the ratings), as well as what the practitioners and/or participants did to restore the session to better functioning. We can also see that the remaining Ames session as well as the two Rutgers sessions had few or no drops, indicating that the practitioners and participants experienced relatively unproblematic going. 


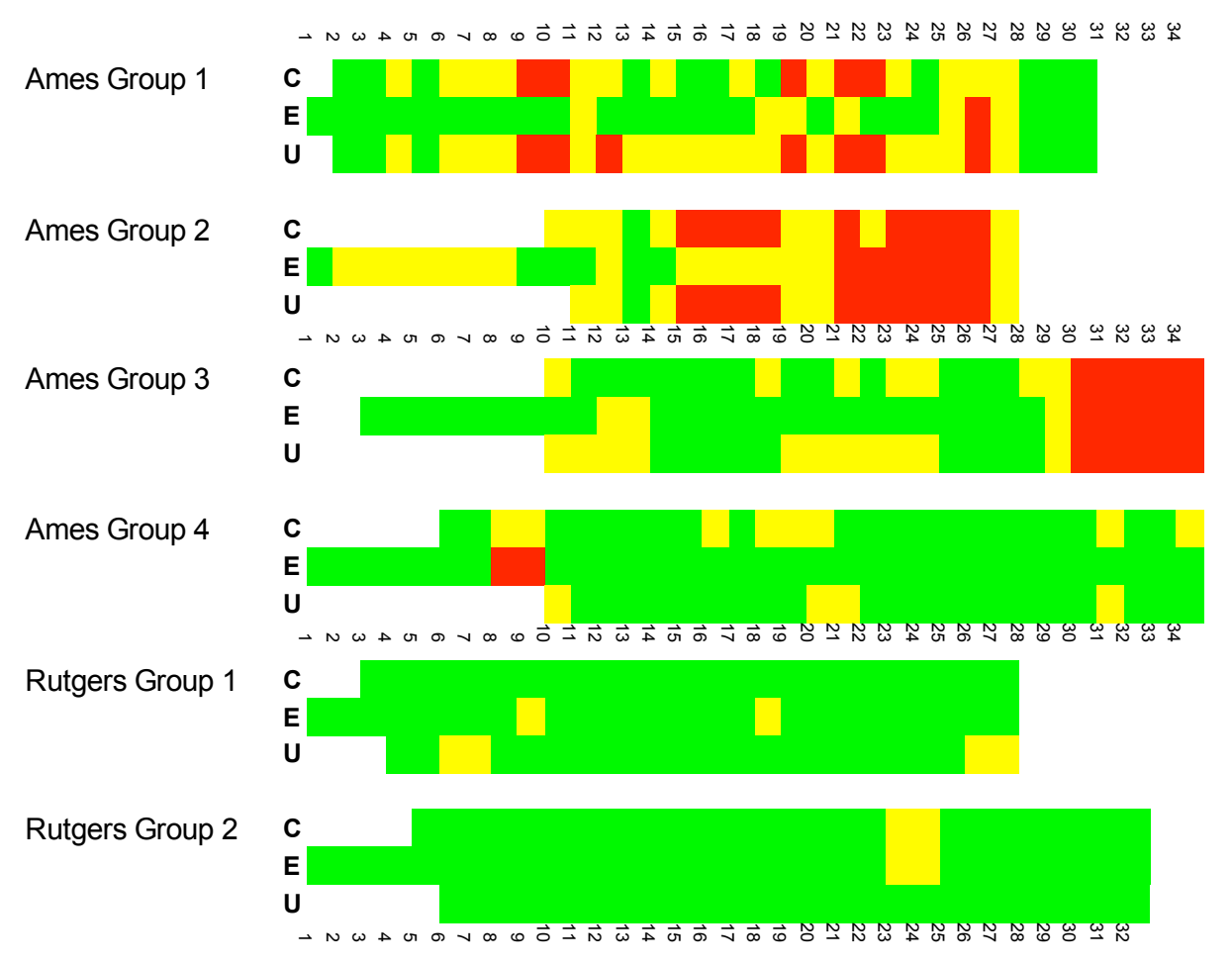

Figure 7. Heat maps from CEU analyses.

In fact those sessions proceeded very close to plan, whereas the Ames groups 1, 2, and 3 all experienced sensemaking challenges.

Other researchers (e.g., Yoong \& Gallupe, 2002) apply to electronic meetings similar coherence and engagement constructs as the ones we invoke here. The main difference is one of granularity of analysis. Our primary interest is closer to the brushstroke level understanding the meaning of the individual practitioner move, when set in context - than the whole-meeting level at which other researchers apply ideas of CEU. At this stage we are not attempting to find inherent relations or patterns among the three criteria, although that may be an outcome of future work.

After reviewing the shaping form and CEU analysis for a session, we selected a particular sensemaking episode for closer analysis. This new analysis started with a narrative description.

\section{Narrative Description}

The narrative description provides a rich delineation of a sensemaking episode within a session. For this, we identified a starting and ending point for the episode, from the point of the sensemaking trigger (an event or anomaly that initiates some sensemaking behavior) to its resolution or culmination. Sometimes there was no resolution per se, for example, when the practitioners were not able to bring a session back on track after a breakdown. For our purposes, this can happen when participants cease engaging with the representation and just talk to each other without any reference to the representation, as the excerpt below describes: 


\begin{abstract}
In the second episode, the session does not recover from a resurgence of more abstract topics. Here, the sensemaking trigger comes in the midst of a coherent discussion of how to tag the two "surface type" comparison nodes that had come out of the previous few moments. At 13:52, participant E sees an opportunity to ask his recurring (abstract $n$ the sense that it is commenting on the software itself, rather than on the subject matter of the exercise) question again, in a different form: "Well that's — so that's a question ... .so in this tagging exercise are we allowed to have alternative or opposing views?" J jumps right in, echoing this kind of question: "And if you have opposing views how do you do it there in the tag?" At first, E's question is absorbed in the discussion of how to tag the nodes, but then another participant, R, moves the discussion solidly in the abstract direction: "So far, I'm afraid, that we have introduced tags in such a way that you can't question a tag." Unlike the previous episode, however, this time no one jumps in to revert the discussion back to direct engagement with the map. Instead, spurred largely by $\mathrm{K}$, the discussion moves to the relatively abstracted topic of how to think about tags in general.
\end{abstract}

Our analysis could not capture all of the narrative threads that perhaps were at work in a session. For example, we did not attempt to describe the individual "stories" (professional interests, emotional experiences, project trajectories) that each participant brought to a session, except when such information might have helped to shed light on the narrative framing or construction at work in the practitioner's actions in a sensemaking episode.

Writing out a narrative description in this manner focused the analysis on the place each move or choice has in the way the sensemaking episode unfolds. We drilled down into even a finer level of detail with the grid analysis.

\title{
Grid Analysis
}

In the grid analysis for each sensemaking episode, we analyzed each practitioner/participant statement or representational move according to a number of criteria. This provided a finegrained understanding of various dimensions of each move, such as the degree and kind of participant engagement with the representation at that moment; the engagement of the practitioner with the participants (e.g., acting in direct response to direction from a participant, or working off to the side to clean up some aspect of the map, or preparing for an upcoming event); the aspects of the setting on which practitioners were focused for that move (participants, maps, text, subject matter, surroundings, or process), and other factors. Mapping each move on the grid required careful consideration about what that move meant in the context of both the session as a whole and within the particular sensemaking episode, sensitizing the analysis in terms of the meaning to both participants and practitioners. Table 5 shows a portion of the taxonomy of concepts used in the grid analysis, derived from open and axial coding through repeated analyses of several long sessions.

The example grid analysis section shown in Figure 8 illustrates six practitioner moves: two verbal statements (at $14 \mathrm{~m} 47 \mathrm{~s}$ and $14 \mathrm{~m} 51 \mathrm{~s}$ ) and four actions on the representation, at $14 \mathrm{~m} 46 \mathrm{~s}, 14 \mathrm{~m} 48 \mathrm{~s}, 14 \mathrm{~m} 51 \mathrm{~s}$ (at the same time as a verbal statement) and $14 \mathrm{~m} 59 \mathrm{~s}$. Four of these moves were done with simultaneous focus on participants (engaged in conversation with them), maps (working on the form of the map), text (working with the text of the map's icons), and the subject matter of the session, while one (the Link move at 14:59) is a shaping move on the map itself. 
Table 5. Move-by-Move Analysis Schema for Grid Analysis.

\begin{tabular}{ll}
\hline Aspect & Description \\
\hline Move Type & $\begin{array}{l}\text { Assigns each practitioner move to a type in a taxonomy of moves in the } \\
\text { Compendium software tool (e.g., Node Move-Arranging, Navigate-Map } \\
\text { Open, etc.), or Verbal move types (Statement/Announcement, } \\
\text { Acknowledgement, Query, Helpful Comment, Exclamation) }\end{array}$ \\
Participant & $\begin{array}{l}\text { Characterizes the degree to which participants are paying attention to the } \\
\text { Engagement with }\end{array}$ \\
Representation & $\begin{array}{l}\text { Partial, and Unclear. The Active value, which refers to moments when } \\
\text { participants are directing the practitioner to perform particular actions on the }\end{array}$ \\
representation, has the subtypes Text, Validation, Navigation, and Structure & Characterizes the degree to which the practitioner is engaged with the \\
Practitioner Response/ & participants during the move. Possible values: Direct, Semi-Direct, \\
Indirect, Delinked. Delinked refers to moves when practitioner attention is \\
focused completely on manipulation of the representation, not interacting \\
or responding to the participants \\
Characterizes what the participant is paying attention to and/or working \\
with during the move. Can be (and often is) multiple. Values: Participants, \\
Maps, Text, Subject Matter, Surroundings, Process
\end{tabular}

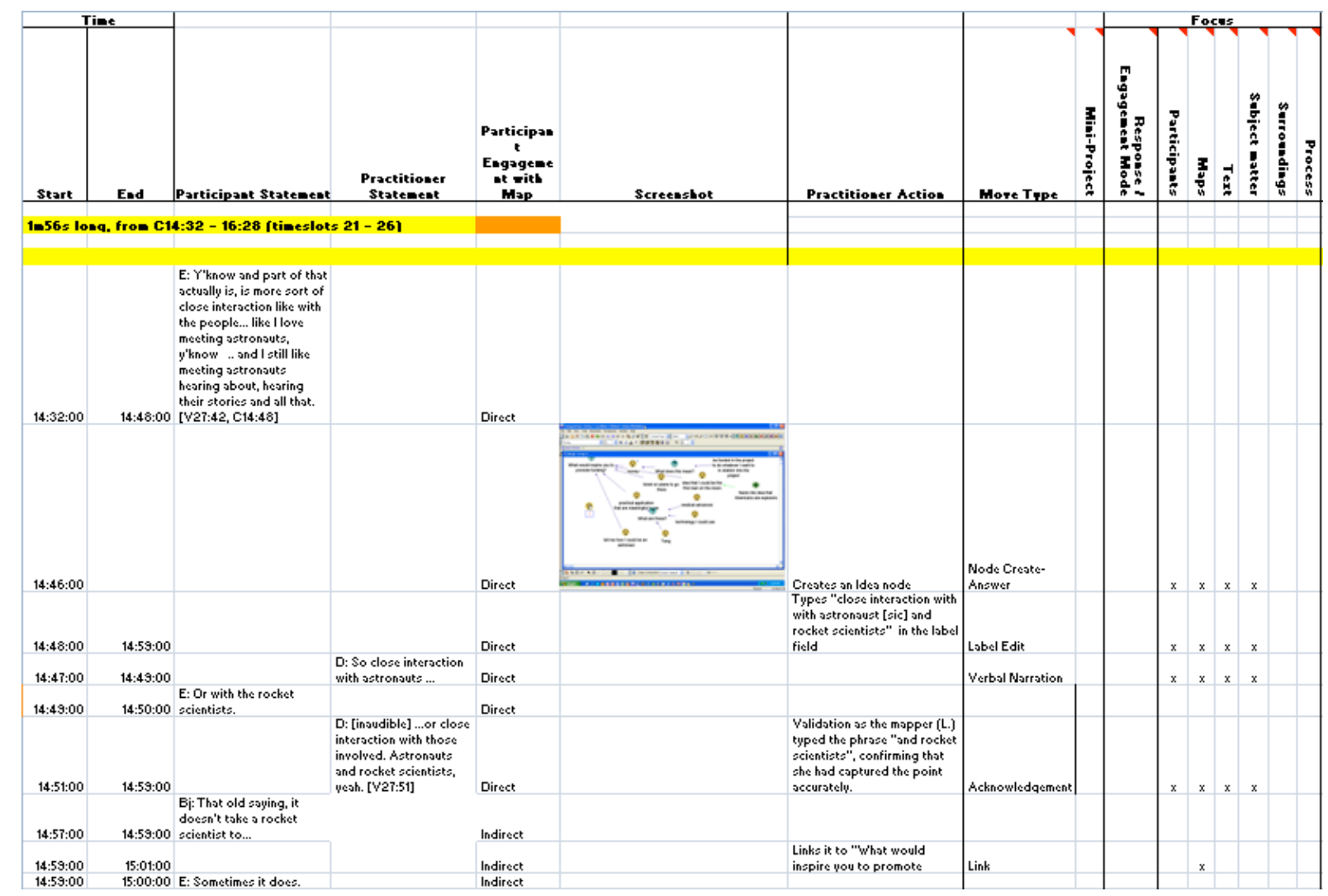

Figure 8. Excerpt from a grid analysis. 
The grid analysis required very close inspection and increased sensitivity to nuances of the data. However, the process clearly demonstrated how much is going on when a skilled PDR practitioner is at work, supporting a team with the digital artifacts and rationale it needs as their deliberations unfold. Moreover, the grid analysis set the stage for characterizing practitioner actions and choices according to a set of criteria derived from the dimensions discussed earlier. We call this the framing analysis.

\section{Framing Analysis}

The framing analysis characterizes practitioner actions during the session in aesthetic, ethical, and experiential terms. It looks at how the practice and context interweave, and in what ways the aesthetic and ethical dimensions of the practice intertwine (McCarthy \& Wright, 2004). We use this as the basis for a normative or ideal model against which we can hold up situations of practice (Aakhus, 2007; Aakhus \& Jackson, 2005). Such a model could be used as a diagnostic tool to analyze what factors are preventing a situation from achieving its potential, or at least to characterize a practice situation in potentially useful ways.

The model used in framing analysis provides a set of components, elements, and exploratory questions to help determine how a context of service, the unique set of people, and the goals, constraints, situation, and subject matter can inform the shaping the practitioner performs on the representational object(s), and vice versa. Understanding and characterizing this has both normative (notions of what practice in such settings should be) and descriptive (how do we look at and characterize situated practice in service) aspects (Aakhus \& Jackson, 2005).

The model contains three columns. ${ }^{4}$ The first (leftmost) column shows the major categories or components of the practitioner's stance-his/her orientation toward various aspects of the situation or practice setting: the practitioner's towards him/herself and his/her own actions, towards the participants, and towards the situation as a whole. The middle column breaks down each stance into elements, each of which is explicitly related to the body of theory it arose from (largely from Bruner, 1990; Dewey, 1934/2005; Schön, 1983, 1987; and McCarthy \& Wright, 2004). These elements constitute an ideal model of practitioner stance; that is, the model specifies the preferred conduct of a PDR practitioner as maintaining a dialogic orientation, fostering a heightened degree of connection between participants, the setting, purpose, and representation, and so on. The elements in turn generate descriptive (characterizing) or normative (evaluating) questions that can help guide the analysis of a particular setting, found in the rightmost column. The rightmost two columns of Component A of the framing model, which addresses the practitioner's own involvement in the situation, are shown in Table 6.

Considering the questions put forward in the framing model involved examining and reflecting on the analytical artifacts produced thus far. Since the framing analysis came last in the analysis sequence, by that time the analyst was very familiar with the specific occurrences in the video recording of the session, and particularly with the nuances of the behavior demonstrated by the practitioners during sensemaking episodes.

For example, in our Ames Group 2 case, we saw the following responses for component A.5, mediated objects and other interventions should preserve openness and dialogicity:

How do the actions of the practitioners inhibit openness and dialogicity?: The prepared map appeared (and was said by participants afterward to be) too complex/involved for participants to engage with, although the mapping of the "needs" section 
did seem to invite dialogue (unfortunately shut off by the mapper). The mapper's verbal intervention served to inhibit the nascent discussion about how to map the "needs" section.

In this case the practitioners needed either to be flexible in how the session would proceed, and evolve the map accordingly (with its extensive prestructuring that the participants were not paying attention to), or to intervene again to bring the session back to the course that they had intended. They could have brought the attention of the group to the portion of the map that contained the desired area of focus and created an effective way for the group to engage with it. As it happened, they stood by and waited to see if the conversation would come back to the intended course of its own accord (rarely an effective strategy).

Table 6. Component A of the Framing Analysis Model.

\section{Element Descriptive and normative questions}

(A.1) Imposing their own coherence and values on a situation

\section{(A.2) Constructing} narratives to account for how the situation arrived at the current pass; causes and breaches in canonicity

(A.3) Eliminating prejudices, preconceptions, and personal desires in their work

(A.4) Personal authenticity in the practice setting

(A.5) Mediated objects and other interventions should preserve openness and dialogicity

(A.6) Artifacts should be clear, expressive, and helpful

(A.7) Perseverance in the face of checks and resistance

(A.8) Clear and focused communication
What coherence is the practitioner imposing on the situation?

What values is the practitioner imposing on the situation?

In what ways are these congruent (or not) with those of the participants?

What is the narrative the practitioner is using to construct the situation?

What is its degree of internal consistency?

How evocative and inclusive is it?

How useful is it?

What prejudices may be active?

What preconceptions may be active?

What personal desires or goals may be active?

In what ways is the practitioner acting in an authentic manner (vs. received, affected, etc.)?

How do the representations the practitioner constructs or modifies foster openness and dialogicity?

How do they inhibit them?

How clear are the artifacts produced/modified by the practitioner? How expressive are they?

How helpful are they within the context of practice?

What checks to forward progress does the practitioner encounter? What resistance from participants, materials, etc. occurs? How does the practitioner respond in the face of these?

How clear is the practitioner's verbal communication? In what ways does the practitioner maintain focus on the aspects of importance in the situation? 


\section{CASE STUDY}

The previous section of this paper introduced the various lenses we have been developing to make sense of PDR practice, illustrated with examples taken from a range of contexts. We now bring these together around a single design session, presenting brief examples of several of the above analyses to show how they provide different kinds of insight.

\section{Setting}

The setting for the session was a workshop for people interested in the Compendium ${ }^{5}$ software tool for mapping multimedia information and design rationale (e.g., as IBIS maps), held at the NASA Ames Research Center, in May 2007. (Compendium is the descendant of the Graphical IBIS [gIBIS] design rationale prototype for mapping IBIS, questions-options-criteria [QOC], and other argumentation structures; Buckingham Shum et al., 2006; Conklin \& Begeman, 1988). Half of one of the two days was given to a segment where less experienced practitioners could plan and facilitate a PDR session and get feedback from more senior practitioners. We divided the informants into groups of three to four and gave them the same general assignment and set of materials. We intended the practice task to be one that required neither expertise with real time use of the software, nor in the subject matter, so that the preparation and practice session could occur within a couple of hours without any advance knowledge on the part of the informants. We chose space travel as the subject matter (reasoning that it was a topic of general interest with which participants could be expected to have at least passing familiarity). We provided a set of 127 images inside Compendium that could be used in the exercise. Informants were informed that the sessions would be recorded for research purposes. They were given advance access to the task materials if they wanted to review them before the workshop.

Each group was given about 90 minutes to prepare (see Figure 9). Some groups included a more experienced practitioner who was allowed to help design and prepare the exercise but not to play an active part during the large group exercise itself.

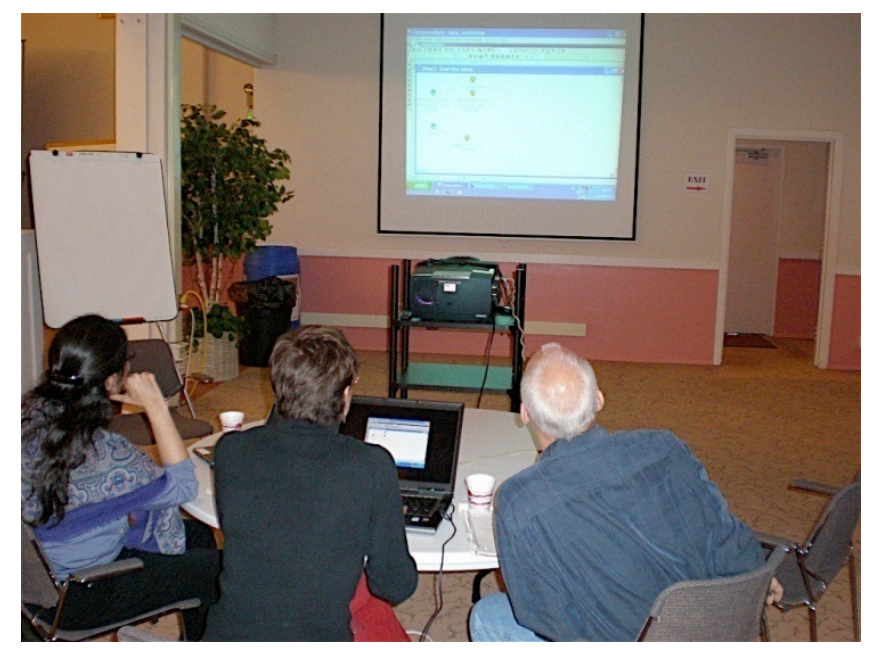

Figure 9. Informants working on their materials for the large group exercise. 
After the preparation period, each group took turns introducing and conducting their session with the larger group of participants. Typically each group had one person acting as the mapper (hands on the keyboard/mouse to control the Compendium hypermedia knowledge mapping software) and one as facilitator (guiding the discussion from in front of the room). Each group had 15 minutes to conduct their session, followed by a debrief discussion in which they also received feedback from the larger group.

In the following section we describe what one of the informant groups (Ames Group 1) encountered in their large group session. The process will be viewed through the lenses of the tools presented above.

\section{Shaping Form Analysis}

The shaping form analysis of Ames Group 1's large group session described how the practitioner team intended the session to proceed as an IBIS discussion of two central questions, for which they had also supplied seed answers. They also intended that each participant's contribution would be tagged with the participants' names, and that the participants would choose an image to correspond with their answer. There was no set outcome, just discussion mapping augmented with the tags and pictures. Both the facilitator and the mapper stayed directly engaged throughout the session. The mapper tried hard to capture all of the discussion on the map and to perform the ancillary tagging task. Both made interventions in the group process, slowing down the discussion at various times and asking for clarification. Both spoke directly to participants and appeared to be trying to get breadth and depth into the discussion as well as to let it and the map evolve. There were some environment issues having to do with how to use the software for elements like font size, which provided brief distractions. The session did experience some breakdowns, mainly when the mapper fell behind in creating a separate map to handle a rather abstract question that came from one of the participants (who himself was trying to understand why other participants kept steering the discussion away from the intended direction). The mapper was trying to perform a series of operations to do this, but new participant contributions came in while she was doing that and she fell behind.

\section{CEU Analysis}

Figure 10 shows the full-session CEU heat map for Ames Group 1. It is apparent from the heat map that timeslots 9-12, 19-22, and 26 contain some sort of anomaly or event that caused the coherence and usefulness scores to drop to the Low level.

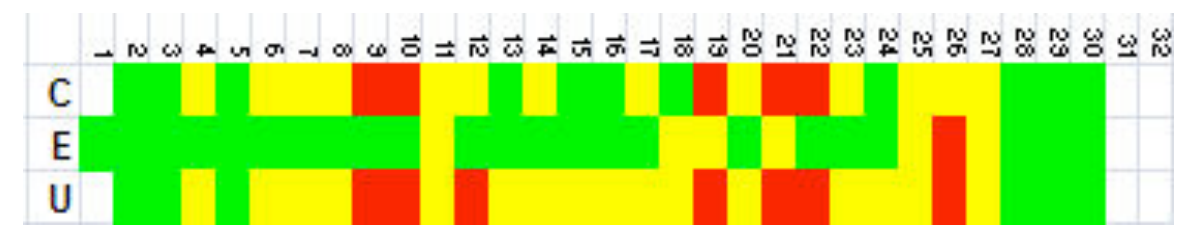

Figure 10. Heat map from Ames Group 1. 
Figure 11 shows a fuller picture of the analytical grid used to develop the CEU ratings for timeslots 19-22 (and the recovery in timeslots 23-24). Here we see a narrative description of the events in each 30-second timeslot, the CEU ratings, and explanations of why each rating was given for each timeslot.

The CEU analysis pictured here provides context for finer-grained analysis of what happened in timeslots 17 through 23, the trajectory of a complete sensemaking episode, starting with a trigger and ending with the resolution.

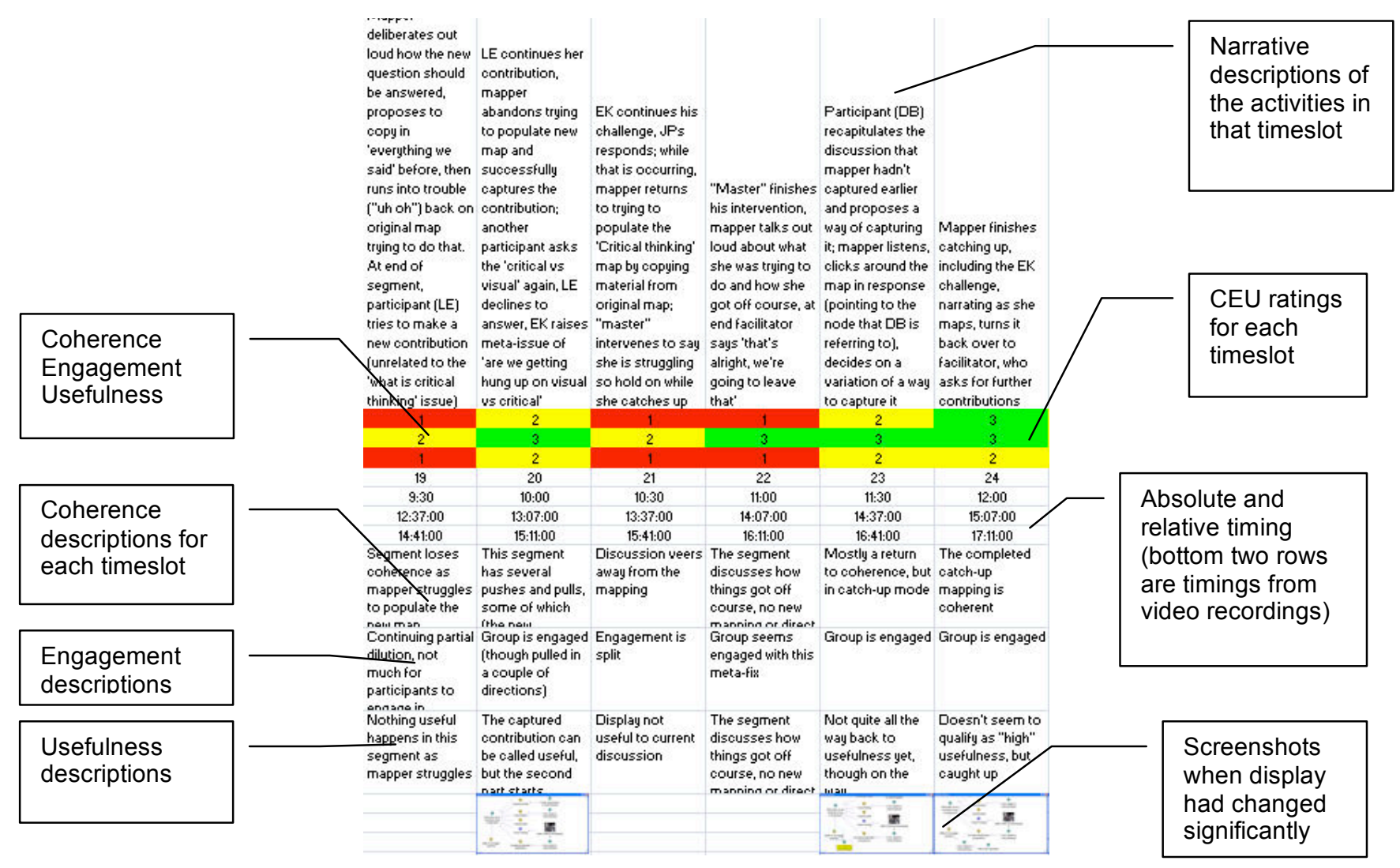

Figure 11. CEU ratings for timeslots 19-24.

\section{Narrative Description of the Sensemaking Episode}

The instance occurred for about 2.5 minutes of the 24 minute session, starting at 13:36 (timeslot 17) and lasting until 16:58 (timeslot 23). The session had proceeded more or less as planned until, at 13:36, one participant (P1) began to challenge some of the contributions to the overall discussion, questioning why some participants kept asking if others' contributions counted as "critical thinking" or "visual thinking" (illustrated on the screenshot in Figure 12).

The challenge did not fit into the expected flow of events, and the mapper, who up to that point had been able to capture participant contributions within the map quite fluidly, lost her way. This constituted the sensemaking trigger. Trying to make the structure of the representation 


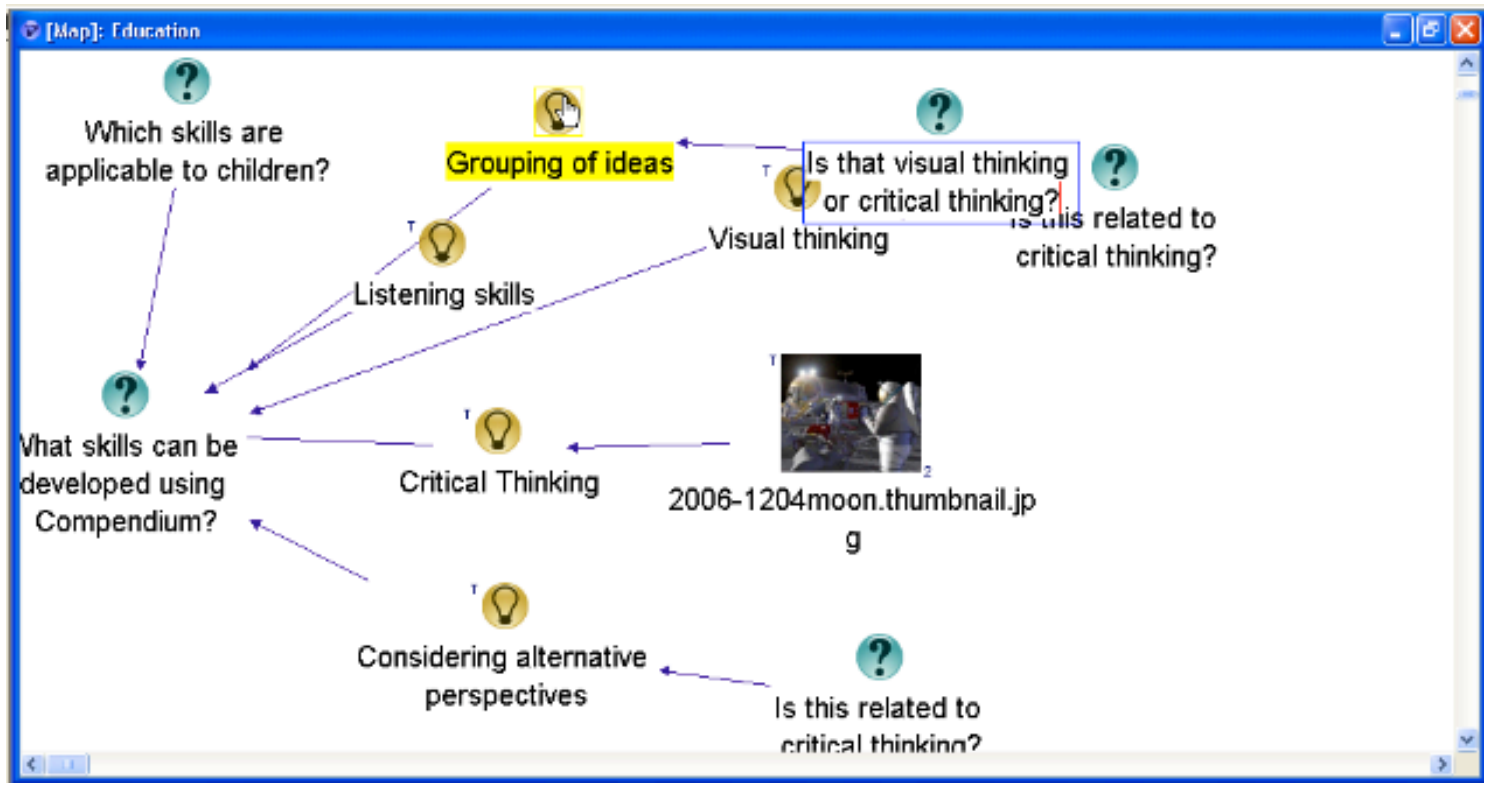

Figure 12. Ames Group 1 session: Map at $13 \mathrm{~m} 36 \mathrm{~s}$.

match the conversation when it veers from the expected course is a frequent challenge in PDR. In this case, this can be seen in Figure 13 in the three question nodes on the right half of the image. Often the planned structure does not seem to contain or fit what people are saying. She began trying to map P1's challenge at 13:49. At 14:42 she was in the midst of doing this when another participant (P2) made a new verbal contribution that did not reference the challenge.

A third participant, $\mathrm{P}$, asked if $\mathrm{P} 2$ 's comment counted as critical thinking or visual thinking, prompting a further challenge from P1. The mapper was able to capture P2's 14:42 contribution on the fly, but could not map either P3's question or P1's new challenge. In the course of this, the mapper got so far behind in mapping P1's challenge that she became stymied.

She faced two overlapping dilemmas. Firstly the participants' issue about how to frame the conversation itself, and secondly her own attempt to regain her momentum and resume making coherent additions to the map. The argument about critical versus visual thinking itself (and whether it was a fit subject for the session) can be seen as the collision of several competing narratives, some of which preceded the event, such as competing ideas for how such discussions should proceed. In this case, after some further back and forth among the participants, a fourth participant ( $\mathrm{P} 4)$ contributed a possible solution. After some negotiation about how much time was left in the session, the mapper asked the room for help in deciding what should be put onto the map. A fifth participant (P5) provided a helpful summary and suggestion for how to represent the discussion.

From that point until the end of the episode at 16:58, the mapper executed a rapid series of moves on the map, which enabled her to bring the map up to the point where it corresponded to the summary provided by participant P5, and to announce at 16:58, "I'm caught up."

In the excerpt, we see improvised actions that draw on practitioner (as well as participant) repertoires. Up to the point of the breach in timeslot 19, the mapper had followed a straightforward, preplanned dialogue mapping approach in her work on the knowledge map. When things went wrong, this had to be (temporarily) abandoned. With the help of several of 
the participants, the mapper was able to recast the situation, which helped her launch a rapid series of actions on the map to bring it back to a point where forward progress, and the dialogue mapping technique, could resume.

\section{Framing Analysis}

In the framing analysis, we relate aspects of the events in the episode to our theoretical framework, such as these aspects that emerged from the framing analysis for Ames Group 1:

What coherence is the practitioner imposing on the situation?

There were two types of imposed coherence: the practitioners' expressed desire for a "clean" discussion map, and attempts to keep the display coherent in the face of divergent and somewhat problematic contributions (in the sense of being hard to fit in or tending to pull the discussion off the intended course). There was a concerted attempt at coming up with coherent structures on the fly to encompass both the primary contributions (the answers to the seed questions) and the meta contributions about visual versus critical thinking, such as the participant statements at 13:36 and 14:51.

What values is the practitioner imposing on the situation? In what ways are these congruent (or not) with those of the participants?

There was a value of inclusiveness, of trying to map everything offered, but also a willingness to set some possible directions aside in the interest of cleanly mapping at least some of the contributions. The mapper had to choose between following all of the possible threads - particularly the pull toward the metaquestions about critical thinking - that some of the participants wanted to pursue versus focusing on cleanly mapping a few. Of necessity some participants' interests got shorter shrift as a result, such as a participant comment about "seeing bigger questions" at 14:42.

What is the narrative the practitioner is using to construct the situation?

The practitioners intended that a "clean" discussion would emerge "naturally" from the seed questions. A breach occurred when the actual discussion did not follow the intended form cleanly. The mapper was smoothly capturing the discussion as it happened, but then divergent input came in which required operations that (a) she was not quick enough at doing, or (b) did not seem to fit coherently.

\section{How evocative and inclusive is it?}

The preplanned, intended narrative set up a canonicity of a cleanly unfolding discussion, in which participants could provide tagged answers with images in response to the clear questions. However the answers started spawning a metadiscussion that broke down, and the practitioners were not able to be completely inclusive of all the contributions.

How do the representations the practitioner constructs or modifies foster openness and dialogicity? 


\begin{abstract}
The seed questions were appropriately open-ended, which lent itself to dialogue (e.g., "What skills can be developed using Compendium?"). The question nodes added during the session were partially so, though some were phrased as yes-or-no questions, which are less open (e.g., "Is this related to critical thinking?"). These were mostly done quickly in response to the metaquestions that were difficult to handle by their nature (e.g., "Is this visual or critical thinking?" or "Why do we keep getting hung up on this question?"). However, by deciding (after some back-and-forth) to link these questions to each answer they pertained to, the practitioners were preserving the opportunity to deal with the metaquestions later, recording them in answer to the concerns of some of the participants, while still keeping the intended discussion course going. A similar dynamic was gained by following the suggestion to open a separate map to address the metaquestion "What is critical thinking?" The possibility of exploring that question later remained open.
\end{abstract}

\title{
Summary
}

We see in these excerpts that the practitioner's actions can be characterized along multiple aesthetic and ethical dimensions. She had to make representational and process choices, which ultimately had consequences for which participant interests would be reflected in what ways. She had to temporarily abandon forward movement so that she could catch up, and reach out for help and suggestions for how to proceed. This proved successful, as she was able to get back on track.

\section{SUMMARY AND DISCUSSION}

In this paper we have described research that looks at the practice level of PDR: the wielding of DR tools in service to groups of people in collaborative, real-time settings. We can now revisit the research questions proposed earlier:

-(RQ1) What is the nature of the skills required to construct graphical knowledge representations in real-time, participatory settings?

-(RQ2) What are the kinds of choices practitioners face, especially at sensemaking moments in the course of conducting sessions?

-(RQ3) How does the context of the service being provided affect the choices a practitioner makes?

Rather than evaluating the PDR tools or methods themselves for RQ1, we took them as a given and focused instead on the human activity of creating the representations, especially on the skills needed and obstacles encountered in keeping DR artifacts coherent, engaging, and useful. For RQ2, we proposed a theoretical framework that has proven helpful in characterizing practitioner choices at sensemaking moments, and described the analytical tools that helped us examine video recordings of practice in light of the framework. For RQ3, we presented brief examples from some of our case studies describing instances of practitioner creativity and improvisation, often occurring as short "flashes," and seen examples of practitioners making aesthetic and ethical choices in the course of managing the multithreaded activities of a PDR session, including discussion of how the context and situation of practice informs the choices and moves practitioners make. 
How does this kind of analysis advance matters? We propose that by looking closely at how actual sessions unfold, and treating their exigencies with the kind of attention given to other forms of professional practice, we elevate the activity of facilitating collaborative representation-making in groups (whether DR, or any other visual language) into a worthy research subject in its own right. This can provide a way for practitioners to deepen their understanding of their work by giving them a variety of means to analyze and reflect on their own practice, and can contribute to development of practitioner guidelines such as those common to other professional practices, such as the coherence guidelines for GSS facilitators proposed by Yoong and Gallupe (2002). The various analytical tools we have developed can contribute toward a methodology for characterizing the aesthetic and ethical dimensions of participatory media practice. These can lead to development of better approaches to practitioner education, thus "helping a student break into manageable parts what had at first appeared to be a seamless flow of movement" (Schön, 1987, p. 112). For example, the framing analysis could be used as a diagnostic tool to analyze what factors are preventing a situation from achieving its potential, or at least to characterize a practice situation in potentially useful ways.

The framework and analysis tools also shed light on the fostering of creativity in design meetings, particularly when rationale is being captured. As we have seen, people taking on the practitioner's role play a key part when teams encounter breakdowns and anomalies in the course of PDR sessions. Such moments, in small and sometimes large ways, can make the difference between success and failure of a design session. Failure can cause frustration and setbacks to a design effort, whereas success in swiftly resolving a breakdown frees up a team to bring their creativity to bear on the design problems rather than on "fixing" the meeting. We have seen how practitioner creativity can emerge when he/she intervenes in a session to restore its forward movement. At its best, practitioner creativity can result in choice, action, and materials seamlessly coming together to resolve the breakdown.

A potential contribution of this research is the development of a typology of dimensions of PDR practice, situations that a practitioner could face and the types of possible actions, such as the partial example in Table 7. Practitioners could use such a table to reflect on what did or did not happen in a particular session, considering the pros and cons of the different approaches given the context.

PDR practice is worthy of investigation in its own right and the methods outlined here provide a practical means and theoretical basis for doing so. These methods also point out how practitioners, tool builders, and consumers of PDR services can better understand how the micro, often tacit, dimensions of a practice shape the form and content of the product namely, the rationale captured. Hence, aesthetics [p], ethics [q], narrative [r], sensemaking [s],

Table 7. Some Common Practice Situations and Example Actions.

\begin{tabular}{ll}
\hline Situation & Possible Actions \\
\hline $\begin{array}{l}\text { Participant topics or } \\
\text { statements that do not fit } \\
\text { the planned structure }\end{array}$ & $\begin{array}{l}\text { Intervene in the conversation to bring it back to intended topic } \\
\text { Evolve the structure on the fly } \\
\text { Too much information and } \\
\text { input coming too fast }\end{array}$ \\
$\begin{array}{l}\text { Ask participants to slow down; be willing to intervene firmly if needed } \\
\text { Capture as much as possible in background, wait for an opportunity } \\
\text { to ask participants what was missed }\end{array}$ \\
\hline
\end{tabular}


and improvisation [ $\mathrm{t}$ ] are consequential for how matters are represented. With the approach described here, we can go much further in understanding how.

In future work we will draw on the foundational considerations outlined in this paper to develop concrete activities for practitioner education, as well as lessons for supporting tool design. We follow McCarthy \& Wright's (2004, p. 62) argument that restoring the "continuity between aesthetic and prosaic experience" can reveal untapped and unexplored dimensions of the human experience of technology, for which more conventional approaches fail to provide tools for understanding. Using felt experience and an aesthetic viewpoint for technology use, they argue, would open up new possibilities for tool design. We will explore what general lessons, heuristics, and guidelines for practice can be drawn from the cases, and develop ways to help practitioners apply them to instances of practice. As a first step, we conducted a session at a gathering of graphic facilitators in August 2009. ${ }^{6}$ Participants evaluated an instance of their own practice (a very different approach than PDR) using the CEU constructs, and reported that it helped them reflect in new ways about their actions.

Taking the practice level seriously means looking closely at what it takes to make sessions run well: how different practitioners overcome the experiential challenges involved in bringing a group of people through such an effort successfully. Partly because we have lived these challenges ourselves in many different contexts, and partly because we strongly believe in the benefits and potential of the approaches, PDR for us is already a professional practice deserving of careful study as an ongoing phenomenon rather than a start-up experiment, moving the question from "Can it work?" to "How can it work better?" Better tools and methods alone may help inculcate a broader interest in the practice level, but developing knowledge and expertise in the practice level can help bring about wider and more effective use of the tools and methods.

\section{ENDNOTES}

1. This case is drawn from an actual project.

2. For the purposes of this paper and project, we illustrated with hypermedia knowledge mapping software to capture the design rationale, but the same considerations apply to other sorts of DR approaches and tools.

3. Analysis artifacts from these studies are available on-line at http://people.kmi.open.ac.uk/selvin/analysis

4. A full version of the framing analysis model with discussion and citations is available at http://people.kmi.open.ac.uk/selvin/analysis/framing.pdf

5. Compendium Institute: http://compendium.open.ac.uk.institute

6. Voices of Visual Practice, 14th Annual International Forum of Visual Practitioners Conference, Montreal, Canada, August 5-7, 2009; http://www.ifvp.org

\section{REFERENCES}

Aakhus, M. (2001). Technocratic and design stances toward communication expertise: How GDSS facilitators understand their work. Journal of Applied Communication Research, 29, 341-371.

Aakhus, M. (2002). Design practice and transparency work in the technological facilitation of collaborative decision making. Unpublished manuscript.

Aakhus, M. (2003). Neither naïve nor critical reconstruction: Dispute mediators, impasse, and the design of argumentation. Argumentation, 17, 265-290. 
Aakhus, M. (2007). Conversations for reflection: Augmenting transitions and transformations in expertise. In C. R. McInerney \& R. E. Day (Eds.), Re-thinking knowledge management: From knowledge objects to knowledge processes (pp. 1-20). Dordrecht, The Netherlands: Springer-Verlag.

Aakhus, M., \& Jackson, S. (2005). Technology, interaction, and design. In K. Fitch \& R. Sanders (Eds.), Handbook of language and social interaction (pp. 411-436). Mahwah, NJ, USA: Lawrence Erlbaum.

Arnheim, R. (1967). Art and visual perception: A psychology of the creative eye. Berkeley, CA; USA: University of California Press.

Bruner, J. (1990). Acts of meaning. Cambridge, MA, USA: Harvard University Press.

Buckingham Shum, S. (1996). Analyzing the usability of a design rationale notation. In T. Moran \& J. Carroll (Eds.), Design rationale: Concepts, techniques, and use (pp. 185-215). Mahwah, NJ, USA: Lawrence Erlbaum.

Buckingham Shum, S., Selvin, A., Sierhuis, M., Conklin, J., Haley, C., \& Nuseibeh, B. (2006). Hypermedia support for argumentation-based rationale: 15 years on from gIBIS and QOC. In A. Dutoit, R. McCall, I. Mistrik, \& B. Paech (Eds.), Rationale management in software engineering (pp. 111-132). Berlin, Germany: Springer-Verlag. Also available at http://oro.open.ac.uk/3032

Clancey, W. J., Sierhuis, M., Alena, R., Berrios, D., Dowding, J., Graham, J. S., Tyree, K. S., Hirsh, R. L., Garry, W. B., Semple, A., Buckingham Shum, S. J., Shadbolt, N., \& Rupert, S. (2005, January-February). Automating CapCom Using Mobile Agents and Robotic Assistants. Paper presented at the American Institute of Aeronautics and Astronautics 1st Space Exploration Conference, Orlando, FL, USA. Available from: AIAA Meeting Papers on Disc [CD-ROM], Reston, VA, and as Advanced Knowledge Technologies ePrint 375: http://eprints.aktors.org/375, pp. 1-41.

Cohen, C. (1997). A poetics of reconciliation: The aesthetic mediation of conflict. Unpublished doctoral dissertation, University of New Hampshire, USA. Available on-line at www.brandeis.edu/ethics/coexistence_initiative/research_and_scholarship/reconciliation.pdf

Conklin, J., \& Begeman, M. (1988). gIBIS: A hypertext tool for exploratory policy discussion. ACM Transactions on Information Systems, 6, 303-331.

Dervin, B. (1983, May). An overview of sense-making research: Concepts, methods, and results to date. Paper presented at the annual meeting of the International Communication Association, Dallas, TX, USA.

Dervin, B. (1992). From the mind's eye of the user: The sense-making qualitative-quantitative methodology. In J. D. Glazier \& R. R. Powell (Eds.), Qualitative research in information management (pp. 61-84). Englewood, CO, USA: Libraries Unlimited.

Dewey, J. (2005). Art as experience. New York: The Berkeley Publishing Group. (Originally published in 1934)

Fortner, R., \& Christians, C. (1981). Separating wheat from chaff in qualitative studies. In G. Stempel \& B. Westley (Eds.), Research methods in mass communication (2nd ed.; pp. 375-387). Englewood Cliffs, NJ, USA: Prentice Hall.

Kunz, W., \& Rittel, H. (1970). Issues as elements of information systems (Working Paper No. 131). Studiengruppe fur Systemforschung, Heidelberg, Germany.

McCarthy, J., \& Wright, P. (2004). Technology as experience. Cambridge, MA, USA: MIT Press.

Murray, K. (n.d.). Narrative partitioning: The ins and outs of identity construction. Retrieved May 3, 2006 from http://home.mira.net/ kmurray/psych/in\&out.html

Rosson, M. B., \& Carroll, J. (2009). Scenario-based design. In A. Sears \& J. Jacko (Eds.), Human-computer interaction: Development process (pp. 1032-1050). Boca Raton, FL, USA: CRC Press/Taylor \& Francis.

Sawyer, K. (1999). Improvised conversations: Music, collaboration and development. Psychology of Music, 27 , 192-205.

Sawyer, K. (2003). Group creativity: music, theater, collaboration. Mahwah, NJ, USA: Lawrence Erlbaum.

Sawyer, K. (2004). Creative teaching: Collaborative discourse as disciplined improvisation. Educational Researcher, 33(2), 12-20.

Schön, D. (1983). The reflective practitioner: How professionals think in action. London: Basic Books. 
Schön, D. (1987). Educating the reflective practitioner: Toward a new design for teaching and learning in the professions. San Francisco: Jossey-Bass.

Selvin, A. (2008). Performing knowledge art: Understanding collaborative cartography. In A. Okada, S. Buckingham Shum, \& T. Sherborne (Eds.), Knowledge cartography: Software tools and mapping techniques (pp. 223-247). London: Springer-Verlag.

Selvin, A., \& Buckingham Shum, S. (2008, April). Narrative, sensemaking, and improvisation in participatory hypermedia construction. Paper presented at the Sensemaking Workshop, CHI 2008: ACM Conference on Computer-Human Interaction, Florence, Italy. Available on-line at http://oro.open.ac.uk/19039

Selvin, A., \& Buckingham Shum, S. (2009, April). Coherence, engagement, and usefulness as sensemaking criteria in participatory media practice. Paper presented at the Sensemaking Workshop, ACM ComputerHuman Interaction (CHI) Conference, Boston, MA, USA. Available on-line at http://oro.open.ac.uk/12910

Sierhuis, M., \& Buckingham Shum, S. (2008). Human-agent knowledge cartography for e-Science: NASA field trials at the Mars Desert Research Station. In A. Okada, S. Buckingham Shum, \& T. Sherborne (Eds.), Knowledge cartography: Software tools and mapping techniques (pp. 287-305). London: Springer-Verlag.

Strauss, A., \& Corbin, J. (1990). Basics of qualitative research: Grounded theory procedures and techniques. Newbury Park, CA, USA: Sage.

Tracy, K. (1989). Conversational dilemmas and the naturalistic experiment. In B. Dervin, L. Grossberg, B. O'Keefe, \& E. Wartella (Eds.), Rethinking communication: Volume 2. Paradigm examples (pp. 411-423). Newbury Park, CA, USA: Sage.

Tripp, D. (1993). Critical incidents in teaching: Developing professional judgment. New York: Routledge.

Weick, K. (1995). Sensemaking in organizations. Thousand Oaks, CA, USA: Sage.

Weick, K., \& Meader, D. (1993). Sensemaking and group support systems. In L. Jessup \& J. Valacich (Eds.), Group support systems: New perspectives (pp. 230-252). New York: Macmillan.

Yoong, P., \& Gallupe, B. (2002). Coherence in face-to-face electronic meetings: A hidden factor in facilitation success. Group Facilitation: A Research and Applications Journal, 4, 12-21. Available also on-line at http://citeseerx.ist.psu.edu/viewdoc/download?doi=10.1.1.125.4454\&rep=rep1\&type=pdf\#page=15

\section{Authors' Note}

Some of the data analysed in this article were gathered from eScience/robotics field trials funded by NASA (Mobile Agents project) and the UK EPSRC (Collaborative Advanced Knowledge Technologies in the Grid project), to whom we are indebted.

All correspondence should be addressed to

Albert M. Selvin

Verizon Information Technology

Knowledge Media Institute

Open University

Milton Keynes UK

alselvin@gmail.com

Human Technology: An Interdisciplinary Journal on Humans in ICT Environments

ISSN 1795-6889

www.humantechnology.jyu.fi 